\title{
Sustainability and Discounted Utilitarianism in Models of Economic Growth
}

\author{
GEIR B. ASHEIM \\ TAPAN MITRA
}

CESIFO WORKING PAPER NO. 2521

CATEGORY 8: RESOURCES AND ENVIRONMENT

JANUARY 2009
An electronic version of the paper may be downloaded
- from the SSRN website:
- from the RePEc website:
www.SSRN.com
- from the CESifo website:
www.RePEc.org
www.CESifo-group.org/wp




\title{
Sustainability and Discounted Utilitarianism in Models of Economic Growth
}

\begin{abstract}
Discounted utilitarianism treats generations unequally and leads to seemingly unappealing consequences in some models of economic growth. Instead, this paper presents and applies sustainable discounted utilitarianism (SDU). SDU respects the interests of future generations and resolves intergenerational conflicts by imposing on discounted utilitarianism that the evaluation be insensitive to the interests of the present generation if the present is better off than the future. An SDU social welfare function always exists. We provide a convenient sufficient condition to identify SDU optima and apply SDU to two well-known models of economic growth. We also investigate the axiomatic basis for SDU.
\end{abstract}

JEL Code: D63, D71, Q01.

Keywords: intergenerational equity, sustainability, discounted utilitarianism, egalitarian consumption streams, efficiency, exhaustible resources.

Geir B. Asheim

Department of Economics

University of Oslo

P.O. Box 1095 Blindern

0317 Oslo

Norway

g.b.asheim@econ.uio.no
Tapan Mitra

Department of Economics

Cornell University

448 Uris Hall

Ithaca, NY 14853

USA

tm19@cornell.edu

December 18, 2008

We thank Wolfgang Buchholz and Bertil Tungodden for many discussions on this and related projects and seminar participants in Ascona, Milan and Toulouse for comments. Asheim gratefully acknowledges the hospitality of Cornell University. 


\section{Introduction}

Both in the theory of economic growth and in the practical evaluation of economic policy with long-term effects (e.g., climate policies), it is common to apply the discounted utilitarian $(D U)$ criterion. DU means that one infinite stream of consumption is deemed better than another if and only if it generates a higher sum of utilities discounted by a constant per period discount factor $\delta$, where $\delta$ is positive and smaller than one.

In spite of its prevalence, DU is controversial, both due to the conditions through which it is justified and due to its consequences for choice in economically relevant situations. As a matter of principle, DU gives less weight to the utility of future generations and therefore treats generations in an unequal manner. If one abstracts from the probability that the world will be coming to an end, thereby assuming that any generation will appear with certainty, it is natural to question whether it is fair to value the utility of future generations less than that of the present one. This criticism has a long tradition in economics, dating back at least to Pigou (1932).

When applied to some models of economic growth, DU leads to seemingly unappealing consequences. In particular, in the model of capital accumulation and resource depletion first analyzed by Dasgupta and Heal (1974) and Solow (1974) which we will henceforth refer to as the Dasgupta-Heal-Solow (DHS) model - the application of DU forces consumption to approach zero as time goes to infinity, even though sustainable streams with constant or increasing consumption are feasible. Moreover, this result holds for any discount factor $\delta$ smaller than one; even when $\delta$ is close to one so that discounting is small. In other words, when applied to the DHS model, the use of DU undermines the livelihood of generations in the far future also when each generation is given almost the same weight as its predecessor.

This motivates the central question posed in this paper: Does there exist an alternative criterion of intergenerational justice satisfying the following desiderata:

(1) The criterion incorporates an equity condition respecting the interests of future generations. 
(2) The criterion resolves intergenerational conflicts by leading to consequences with ethical appeal, in particular when applied to the DHS model, as well as to the usual one-sector model of economic growth (the Ramsey model).

In our investigation, we adopt a setting that allows for easy comparison with DU, as axiomatized by Koopmans (1960). In particular, we remain within Koopmans' (1960) framework, by requiring our criterion (a) to be representable by a numerical social welfare function (SWF), (b) to satisfy Koopmans' (1960) stationarity condition, and (c) to retain some sensitivity to the interest of the present generation.

One way of ensuring that generations are treated in an equal manner is to insist on the procedural equity condition of Finite Anonymity. Finite Anonymity means that a finite permutation of a consumption stream leads to an alternative stream that is equally good in social evaluation. Finite Anonymity has the interesting property that - when combined with the Pareto principle in models of economic growth - it rules out streams that are not non-decreasing, provided that the technology satisfies a productivity condition (see Asheim, Buchholz and Tungodden, 2001). Since a DHS technology is productive in this sense, Finite Anonymity combined with the Pareto principle entails that only efficient and non-decreasing streams are acceptable. In particular, it thus formalizes the ethical intuition that deems as unacceptable the consequences of discounted utilitarianism in the setting of DHS technologies.

However, as demonstrated by Basu and Mitra (2003), there exists no numerically representable welfare function which satisfies both Finite Anonymity and the Pareto principle. In fact, Finite Anonymity is hard to combine with any kind of sensitivity to the interests of each generation, as long as one requires numerical representability (see Basu and Mitra, 2007).

An alternative is to apply the axiom of Hammond Equity for the Future (HEF), which is a weak consequentialist equity condition introduced by Asheim and Tungodden (2004) and analyzed by Asheim, Mitra and Tungodden (2007, 2008) and Banerjee (2006). HEF captures the following ethical intuition: A sacrifice by the present generation leading to a uniform gain for all future generations cannot yield 
a consumption stream that is less desirable in social evaluation if the present remains better off than the future even after the sacrifice. Under certain consistency requirements on the social preferences, HEF is not only weaker than the ordinary Hammond Equity condition, but it is also implied by other consequentialist equity conditions like the Pigou-Dalton principle of transfers and the Lorenz Domination principle (see Asheim, Mitra and Tungodden, 2007, for details). Hence, it can be endorsed both from an egalitarian and a utilitarian point of view.

Combined with continuity, HEF entails that social evaluation is sensitive to the interests of the present generation only when the present is worse off than the future. As investigated in our companion paper, Asheim, Mitra and Tungodden (2008), the axiom can be introduced in the Koopmans framework, in which it can be used to justify what we there refer to as a sustainable recursive $S W F$.

The purpose of the current paper is to apply the concept of sustainable recursive SWFs to two important classes of technologies used to model economic growth: Ramsey technologies and DHS technologies. We thereby demonstrate the applicability of this concept and allow judgements to be made on its consequences in these models. For reasons of tractability we consider a small modification of DU consistent with the condition of HEF. The resulting criterion - which we refer to as the sustainable discounted utilitarian (SDU) criterion - is within the class of sustainable recursive SWFs and allows for easy comparison with DU.

In Section 2 we present the formal definition of an SDU SWF: an SWF is SDU if it satisfies four requirements. While three of these requirements are also satisfied by DU, one departs from DU by requiring that an SDU SWF not be sensitive to the interests of the present generation if the present is better off than the future. This requirement ensures that an SDU SWF satisfies HEF. In Section 3 we provide a convenient sufficient condition to identify SDU optimum streams within any given set of feasible streams. In Section 4 we consider the class of Ramsey technologies and characterize the set of SDU optimum streams in this environment through Theorem 1. Likewise, in Section 5 we apply results from earlier work (Dasgupta and Mitra, 
1983; Asheim, 1988) and characterize the set of SDU optimum streams in the class of DHS technologies through Theorem 2. In Section 6 we discuss how SDU resolves distributional conflicts between generations; in particular, in DHS technologies the use of SDU leads to development at first when capital is productive, while protecting the generations in the distant future from the grave consequences of discounting when the vanishing resource stock undermines capital productivity. In an appendix we establish that an SDU SWF always exists and is unique within the subset of bounded streams. Moreover, we show that any SDU SWF is a sustainable recursive SWF by verifying that all the axioms characterizing the latter concept are satisfied.

\section{Sustainable discounted utilitarian SWFs}

Denote by $\mathbb{R}_{+}$the set of all non-negative real numbers, by $\mathbb{R}_{++}$the set of all positive real numbers, by $\mathbb{Z}_{+}$the set of all non-negative integers, and by $\mathbb{N}$ the set of all positive integers. Denote by ${ }_{0} \mathbf{x}=\left(x_{0}, x_{1}, \ldots, x_{t}, \ldots\right) \in \mathbb{R}_{+}^{\mathbb{Z}_{+}}$an infinite stream of consumption where, for $t \in \mathbb{Z}_{+}, x_{t}$ is a non-negative indicator of the well-being of generation $t$. Define, for $T \in \mathbb{N},{ }_{0} \mathbf{x}_{T-1}=\left(x_{0}, \ldots, x_{T-1}\right)$ and ${ }_{T} \mathbf{x}=\left(x_{T}, x_{T+1}, \ldots\right)$; these are, respectively, the $T$-head and the $T$-tail of ${ }_{0} \mathbf{x}$. A consumption stream ${ }_{0} \mathbf{x}$ is called egalitarian if $x_{t}=x_{t+1}$ for all $t \in \mathbb{Z}_{+}$.

Utility in a period is derived from consumption in that period alone. The utility function $U: \mathbb{R}_{+} \rightarrow \mathbb{R}$ is assumed to satisfy:

$U$ is strictly increasing, strictly concave, and continuous on $\mathbb{R}_{+}$

$U$ is continuously differentiable on $\mathbb{R}_{++}$, and $U^{\prime}(x) \rightarrow \infty$ as $x \rightarrow 0$.

Denote by $\delta \in(0,1)$ the utility discount factor. Consider the following classes of infinite consumption streams:

$$
\begin{aligned}
& \mathbf{X}_{\delta}:=\left\{{ }_{0} \mathbf{x} \in \mathbb{R}_{+}^{\mathbb{Z}_{+}} \mid \sum_{t=0}^{\infty} \delta^{t} x_{t}<\infty\right\} \\
& \mathbf{X}_{\varphi}:=\left\{{ }_{0} \mathbf{x} \in \mathbb{R}_{+}^{\mathbb{Z}_{+}} \mid{ }_{0} \mathbf{x} \text { is bounded }\right\} .
\end{aligned}
$$

Note that, if $0<\delta^{\prime}<\delta^{\prime \prime}<1$, then $\mathbf{X}_{\delta^{\prime}} \supsetneq \mathbf{X}_{\delta^{\prime \prime}} \supsetneq \bigcap_{\delta \in(0,1)} \mathbf{X}_{\delta} \supsetneq \mathbf{X}_{\varphi}$. 
Given any $\delta \in(0,1)$, the SWF $w: \mathbf{X}_{\delta} \rightarrow \mathbb{R}$ defined by

$$
w\left({ }_{0} \mathbf{x}\right):=(1-\delta) \sum_{t=0}^{\infty} \delta^{t} U\left(x_{t}\right)
$$

is the discounted utilitarian (DU) SWF. It follows from (U.1) that $w$ is well-defined. Multiplying the sum of discounted utilities by $1-\delta$ ensures that $w\left({ }_{0} \mathbf{x}\right)=U\left(x_{0}\right)$ if ${ }_{0} \mathbf{X}$ is egalitarian.

The sustainable discounted utilitarian (SDU) SWF modifies DU in the following manner. Given any $\delta \in(0,1)$, an SWF $W: \mathbf{X}_{\delta} \rightarrow \mathbb{R}$ is SDU if

$$
\begin{aligned}
& W\left({ }_{0} \mathbf{x}\right)= \begin{cases}(1-\delta) U\left(x_{0}\right)+\delta W\left({ }_{1} \mathbf{x}\right) & \text { if } U\left(x_{0}\right) \leq W\left({ }_{1} \mathbf{x}\right) \\
W\left({ }_{1} \mathbf{x}\right) & \text { if } U\left(x_{0}\right)>W\left({ }_{1} \mathbf{x}\right),\end{cases} \\
& W\left({ }_{0} \mathbf{x}\right)=U\left(x_{0}\right) \quad \text { if }{ }_{0} \mathbf{x} \text { is egalitarian, } \\
& W\left({ }_{0} \mathbf{x}^{\prime}\right) \geq W\left({ }_{0} \mathbf{x}^{\prime \prime}\right) \quad \text { if }{ }_{0} \mathbf{x}^{\prime} \geq{ }_{0} \mathbf{x}^{\prime \prime}, \\
& \lim _{T \rightarrow \infty} \delta^{T} W\left({ }_{T} \mathbf{x}\right)=0 .
\end{aligned}
$$

Requirement (W.1) departs from DU by requiring that an SDU SWF not be sensitive to the interests of the present generation if the present is better off than the future. In constrast, the other three requirements defining an SDU SWF, (W.2)-(W.4), are also satisfied by DU. They are restrictions which are independent of (W.1).

Consider the following algorithmic construction. For any stream ${ }_{0} \mathbf{x} \in \mathbf{X}_{\delta}$ and each $T \in \mathbb{N}$, construct the finite sequence:

$$
\left.\begin{array}{l}
z(T, T)=w(T \mathbf{x}) \\
z(T-1, T)=\min \left\{(1-\delta) U\left(x_{T-1}\right)+\delta z(T, T), z(T, T)\right\} \\
\ldots \\
z(0, T)=\min \left\{(1-\delta) U\left(x_{0}\right)+\delta z(1, T), z(1, T)\right\} .
\end{array}\right\}
$$

Define the mapping $\bar{W}: \mathbf{X}_{\delta} \rightarrow \mathbb{R}$ by

$$
\bar{W}\left({ }_{0} \mathbf{x}\right):=\lim _{T \rightarrow \infty} z(0, T) .
$$

In the appendix of this paper we show existence of an SDU SWF by establishing that $\bar{W}$ is well-defined by $(\overline{\mathrm{W}})$ and satisfies (W.1)-(W.4). Moreover, we show that, 
if $W$ is an SDU SWF, then $W\left({ }_{0} \mathbf{x}\right) \leq \bar{W}\left({ }_{0} \mathbf{x}\right)$ for ${ }_{0} \mathbf{x} \in \mathbf{X}_{\delta}$ and $\left.W{ }_{0} \mathbf{x}\right)=\bar{W}\left({ }_{0} \mathbf{x}\right)$ for ${ }_{0} \mathbf{x} \in \mathbf{X}_{\varphi}$. Hence, $\bar{W}$ yields an upper bound on SDU welfare for all consumption streams and is the unique SDU SWF restricted to bounded streams.

In the appendix we also establish that any SDU SWF is a sustainable recursive SWF; cf. Asheim, Mitra and Tungodden (2008) who define and provide an axiomatization of this class of SWFs.

The following result provides a basic relationship between SDU and DU SWFs.

Proposition 1 Assume that $W$ is an $S D U S W F$.

(i) If ${ }_{0} \mathbf{x} \in \mathbf{X}_{\delta}$, then, for all $t \in \mathbb{Z}_{+}, W\left({ }_{0} \mathbf{x}\right) \leq W\left({ }_{t} \mathbf{x}\right) \leq w\left({ }_{t} \mathbf{x}\right)$

(ii) If ${ }_{0} \mathbf{x} \in \mathbf{X}_{\varphi}$ is a non-decreasing stream, then $W\left({ }_{0} \mathbf{x}\right)=w\left({ }_{0} \mathbf{x}\right)$.

Proof. Part (i). It follows from (W.1) that, for all $t \in \mathbb{Z}_{+}$,

$$
W\left({ }_{t} \mathbf{x}\right)=\min \left\{(1-\delta) U\left(x_{t}\right)+\delta W\left({ }_{t+1} \mathbf{x}\right), W\left({ }_{t+1} \mathbf{x}\right)\right\} \leq W\left({ }_{t+1} \mathbf{x}\right) .
$$

Hence, $W\left({ }_{0} \mathbf{x}\right) \leq W\left({ }_{t} \mathbf{x}\right)$.

By Lemma 9 of the appendix, for all $t \in \mathbb{Z}_{+}, W\left({ }_{t} \mathbf{x}\right) \leq w\left({ }_{t} \mathbf{x}\right)$.

Part (ii). This result follows from the definitions of $\bar{W}$ and $w$, using Proposition 7 of the appendix, which shows that $W\left({ }_{0} \mathbf{x}\right)=\bar{W}\left({ }_{0} \mathbf{x}\right)$ for all ${ }_{0} \mathbf{x} \in \mathbf{X}_{\varphi}$.

\section{Sustainable discounted utilitarian optimum}

We now introduce the notions of feasibility and optimum in our study. Let $\mathbb{X} \subset \mathbf{X}_{\delta}$ denote the set of feasible consumption streams; it will be assumed to be non-empty and convex. This set will be determined by the technology available over time to transform inputs into outputs, and on the initial stocks of the various inputs available to an economy. In the next two sections, we will see how the set of feasible consumption streams is obtained, starting with the more primitive information of technology and available resources. 
Given a discount factor $\delta$ and utility function $U$ satisfying (U.1) and (U.2), a consumption stream ${ }_{0} \overline{\mathbf{x}} \in \mathbb{X}$ will be called $S D U$ optimum if, for some $W: \mathbf{X}_{\delta} \rightarrow \mathbb{R}$ satisfying (W.1)-(W.4):

$$
W\left({ }_{0} \mathbf{x}\right) \leq W\left({ }_{0} \overline{\mathbf{x}}\right) \text { for all }{ }_{0} \mathbf{x} \in \mathbb{X}
$$

This definition entails that ${ }_{0} \overline{\mathbf{x}} \in \mathbb{X}$ is a unique SDU optimum if, for every $W: \mathbf{X}_{\delta} \rightarrow$ $\mathbb{R}$ satisfying (W.1)-(W.4):

$$
W\left({ }_{0} \mathbf{x}\right)<W\left({ }_{0} \overline{\mathbf{x}}\right) \text { for all }{ }_{0} \mathbf{x} \in \mathbb{X},{ }_{0} \mathbf{x} \neq{ }_{0} \overline{\mathbf{x}} .
$$

Similarly, a consumption stream ${ }_{0} \mathbf{x}^{\prime} \in \mathbb{X}$ will be called $D U$ optimum if:

$$
w\left({ }_{0} \mathbf{x}\right) \leq w\left({ }_{0} \mathbf{x}^{\prime}\right) \text { for all }{ }_{0} \mathbf{x} \in \mathbb{X}
$$

We now provide a convenient sufficient condition for an egalitarian consumption stream to be the unique SDU optimum.

Proposition 2 Let ${ }_{0} \mathbf{x}^{e} \gg 0$ be an egalitarian consumption stream in $\mathbb{X}$. Assume that there exists a price sequence ${ }_{0} \mathbf{p}=\left(p_{0}, p_{1}, p_{2}, \ldots\right) \gg 0$ satisfying

$$
\begin{aligned}
& p_{t+1} / p_{t} \geq \delta \quad \text { for } t \geq 0, \\
& \infty>\sum_{t=0}^{\infty} p_{t} x_{t}^{e} \geq \sum_{t=0}^{\infty} p_{t} x_{t}
\end{aligned}
$$

for every consumption stream ${ }_{0} \mathbf{x} \in \mathbb{X}$. Then ${ }_{0} \mathbf{x}^{e}$ is the unique SDU optimum.

Proof. Suppose that ${ }_{0} \mathbf{x}$ is a feasible consumption stream, distinct from ${ }_{0} \mathbf{x}^{e}$, with $W\left({ }_{0} \mathbf{x}\right) \geq W\left({ }_{0} \mathbf{x}^{e}\right)$ for some $W: \mathbf{X}_{\delta} \rightarrow \mathbb{R}$ satisfying (W.1)-(W.4). Then, by (W.3) and Proposition 1,

$$
w\left({ }_{t} \mathbf{x}^{e}\right)=w\left({ }_{0} \mathbf{x}^{e}\right)=U\left(x_{0}^{e}\right)=W\left({ }_{0} \mathbf{x}^{e}\right) \leq W\left({ }_{0} \mathbf{x}\right) \leq W\left({ }_{t} \mathbf{x}\right) \leq w\left({ }_{t} \mathbf{x}\right) .
$$

For $t \geq 0$, write

$$
A_{t}:=\sum_{\tau=t}^{\infty} \delta^{\tau}\left(x_{\tau}-x_{\tau}^{e}\right),
$$

where the infinite sum in (5) is absolutely convergent and therefore convergent, given that ${ }_{0} \mathbf{x} \in \mathbb{X} \subseteq \mathbf{X}_{\delta}$. Thus, $A_{t} \in \mathbb{R}$ for $t \geq 0$. 
Using (U.1)-(U.2) and the fact that ${ }_{0} \mathbf{x}^{e} \gg 0$ is egalitarian, we have for $\tau \geq 0$,

$$
U\left(x_{\tau}\right)-U\left(x_{\tau}^{e}\right) \leq U^{\prime}\left(x_{\tau}^{e}\right)\left(x_{\tau}-x_{\tau}^{e}\right)=U^{\prime}\left(x_{0}^{e}\right)\left(x_{\tau}-x_{\tau}^{e}\right)
$$

with strict inequality in (6) if $x_{\tau} \neq x_{\tau}^{e}$. Also, for $t \geq 0$,

$$
w\left({ }_{t} \mathbf{x}\right)-w\left({ }_{t} \mathbf{x}^{e}\right)=\frac{1-\delta}{\delta^{t}} \cdot \sum_{\tau=t}^{\infty} \delta^{\tau}\left(U\left(x_{\tau}\right)-U\left(x_{\tau}^{e}\right)\right) .
$$

Combining (5), (6) and (7), we have

$$
w\left({ }_{t} \mathbf{x}\right)-w\left({ }_{t} \mathbf{x}^{e}\right) \leq \frac{1-\delta}{\delta^{t}} \cdot U^{\prime}\left(x_{0}^{e}\right) A_{t}
$$

for $t \geq 0$, with strict inequality in (8) for $t=0$. Combining (4) and (5), we have

$$
A_{0}>0 \text { and } A_{t} \geq 0 \text { for all } t \geq 1
$$

For $t \geq 0$, write

$$
a_{t}:=\delta^{t}\left(x_{t}-x_{t}^{e}\right), \quad b_{t}:=\frac{p_{t}}{\delta^{t}} .
$$

Note that, by (4) and (10), $A_{t}-A_{t+1}=a_{t}$ for all $t \geq 0$, and, by (2),

$$
b_{t+1}-b_{t}=\frac{p_{t+1}}{\delta^{t+1}}-\frac{p_{t}}{\delta^{t}}=\frac{p_{t}}{\delta^{t+1}} \cdot\left(\frac{p_{t+1}}{p_{t}}-\delta\right) \geq 0
$$

for all $t \geq 0$. Then, for all $T \geq 0$, we have (using Abel's partial summation method)

$$
\begin{aligned}
\sum_{t=0}^{T} a_{t} b_{t} & =\left(A_{0}-A_{1}\right) b_{0}+\cdots+\left(A_{T}-A_{T+1}\right) b_{T} \\
& =A_{0} b_{0}+A_{1}\left(b_{1}-b_{0}\right)+\cdots+A_{T}\left(b_{T}-b_{T-1}\right)-A_{T+1} b_{T} \\
& \geq A_{0} b_{0}-A_{T+1} b_{T}
\end{aligned}
$$

where the inequality in (12) follows from (9) and (11). For $T \geq 0$, we get

$$
\begin{aligned}
A_{T+1} b_{T} & =\left(\sum_{\tau=T+1}^{\infty} \delta^{\tau}\left(x_{\tau}-x_{\tau}^{e}\right)\right) \cdot \frac{p_{T}}{\delta^{T}} \\
& =\delta p_{T} \cdot\left[\left(\sum_{\tau=T+1}^{\infty} \delta^{\tau-(T+1)} x_{\tau}\right)-\frac{x_{T+1}^{e}}{1-\delta}\right]<\sum_{\tau=T+1}^{\infty} p_{\tau} x_{\tau}
\end{aligned}
$$

since $x_{\tau}^{e}=x_{T+1}^{e}>0$ and $p_{\tau} / p_{T} \geq \delta^{\tau-T}$ for all $\tau>T$. By (3), $\lim _{T \rightarrow \infty} \sum_{\tau=T+1}^{\infty} p_{\tau} x_{\tau}$ $=0$. Using this fact in (13), we obtain

$$
\lim _{T \rightarrow \infty} A_{T+1} b_{T}=0 .
$$


It follows from (9) and (14) that, for any $\varepsilon \in\left(0, A_{0} b_{0}\right)$, there exists $\tilde{T}$ such that, for all $T \geq \tilde{T}, A_{T+1} b_{T} \leq A_{0} b_{0}-\varepsilon$. Hence, by (10) and (12), for all $T \geq \tilde{T}$,

$$
\sum_{t=0}^{T} p_{t}\left(x_{t}-x_{t}^{e}\right)=\sum_{t=0}^{T} a_{t} b_{t} \geq A_{0} b_{0}-A_{T+1} b_{T} \geq \varepsilon>0 .
$$

This contradicts (3) and shows that there is no feasible stream ${ }_{0} \mathbf{x}$, distinct from ${ }_{0} \mathbf{x}^{e}$, with $W\left({ }_{0} \mathbf{x}\right) \geq W\left({ }_{0} \mathbf{x}^{e}\right)$.

\section{Ramsey technologies}

A Ramsey technology (following Ramsey, 1928) is determined by a sequence of production functions ${ }_{0} \mathbf{g}=\left(g_{0}, g_{1}, g_{2}, \ldots\right)$ where, for each $t, g_{t}: \mathbb{R}_{+} \rightarrow \mathbb{R}_{+}$satisfies

$$
\begin{aligned}
& g_{t} \text { is concave, continuous and increasing on } \mathbb{R}_{+}, \\
& g_{t} \text { is continuously differentiable on } \mathbb{R}_{++}, \\
& g_{t}(0)=0, \quad g_{t}^{\prime}>0 \text { on } \mathbb{R}_{++} .
\end{aligned}
$$

For each $t$, the gross output function $f_{t}$ is defined by $f_{t}(k)=g_{t}(k)+k$ for all $k \geq 0$.

Let $y$ denote gross output, which is split into consumption $x$ and capital input $k$. A program $\left({ }_{t} \mathbf{y},{ }_{t} \mathbf{k}\right)$ is $y_{t}-$ feasible if there exist ${ }_{t} \mathbf{k}$ and ${ }_{t+1} \mathbf{y}$ satisfying

$$
0 \leq k_{\tau} \leq y_{\tau} \quad \text { and } \quad 0 \leq y_{\tau+1} \leq f_{\tau}\left(k_{\tau}\right) \quad \text { for all } \tau \geq t
$$

The consumption ${ }_{t} \mathbf{x}$ associated with a $y_{t}$-feasible program $\left({ }_{t} \mathbf{y},{ }_{t} \mathbf{k}\right)$ is defined by $x_{\tau}=y_{\tau}-k_{\tau}$ for all $\tau \geq t$. A $y_{t}$-feasible program $\left({ }_{t} \mathbf{y},{ }_{t} \mathbf{k}\right)$ is called egalitarian if the consumption stream ${ }_{t} \mathbf{x}$ associated with it is egalitarian. A $y_{t}$-feasible program $\left({ }_{t} \overline{\mathbf{y}},{ }_{t} \mathbf{\mathbf { k }}\right)$ is $y_{t}$-efficient if there is no $y_{t}$-feasible program $\left({ }_{t} \mathbf{y},{ }_{t} \mathbf{k}\right)$ satisfying $x_{\tau} \geq \bar{x}_{\tau}$ for all $\tau \geq t$, with strict inequality for some $\tau \geq t$.

The set $\mathbb{X} \subset \mathbb{R}_{+}^{\mathbb{Z}_{+}}$of feasible consumption streams, introduced in the previous section, can be described for Ramsey technologies by:

$$
\begin{aligned}
& \mathbb{X}=\left\{{ }_{0} \mathbf{X} \in \mathbb{R}_{+}^{\mathbb{Z}_{+}} \mid{ }_{0} \mathbf{X}\right. \text { is a consumption stream associated } \\
& \text { with a } \left.y_{0} \text {-feasible program }\left({ }_{0} \mathbf{y},{ }_{0} \mathbf{k}\right)\right\} \text {. }
\end{aligned}
$$


Combined with the results of Cass and Yaari (1971), Proposition 2 implies the following sufficient condition for a unique SDU optimum.

Proposition 3 Consider a Ramsey technology satisfying (g.1)-(g.3) and $\mathbb{X} \subseteq \mathbf{X}_{\delta}$. Assume that the $y_{0}$-feasible program $\left({ }_{0} \mathbf{y}^{e},{ }_{0} \mathbf{k}^{e}\right)$ is egalitarian and $y_{0}$-efficient with $\left({ }_{0} \mathbf{y}^{e},{ }_{0} \mathbf{k}^{e}\right) \gg 0$, and satisfies:

$$
\begin{aligned}
& \delta f_{t}^{\prime}\left(k_{t}^{e}\right) \leq 1 \quad \text { for } t \geq 0, \\
& \lim _{T \rightarrow \infty} \sum_{t=0}^{T}\left[\frac{1}{\prod_{\tau=0}^{t} f_{\tau}^{\prime}\left(k_{\tau}^{e}\right)}\right]<\infty .
\end{aligned}
$$

Then $\left({ }_{0} \mathbf{y}^{e},{ }_{0} \mathbf{k}^{e}\right)$ is the unique SDU optimum.

Proof. Since ${ }_{0} \mathbf{k}^{e} \gg 0$, the price sequence ${ }_{0} \mathbf{p} \gg 0$ determined by

$$
p_{0}=1 \quad \text { and } \quad p_{t+1} f_{t}^{\prime}\left(k_{t}^{e}\right)=p_{t} \quad \text { for all } t \geq 0
$$

is well-defined. Then (15) implies that (2) is satisfied and (16) implies that $\sum_{t=0}^{\infty} p_{t} x_{t}^{e}$ $<\infty$, and so (3) follows from the Corollary of Cass and Yaari (1971, p. 338). Hence, Proposition 3 follows from Proposition 2.

We now specialize our discussion to the case in which the production functions for the various time periods are the same, and the net capital productivity approaches zero as the capital stock approaches infinity. This is expressed formally in

$$
\begin{aligned}
& g_{t}=g \text { for all } t \geq 0, \\
& \lim _{k \rightarrow \infty} g^{\prime}(k)=0 .
\end{aligned}
$$

Write the gross output function as $f(k)=g(k)+k$.

It follows from (g.1)-(g.5) that, for every $y>0$, there exists a unique $x(y)$, satisfying $0<x(y)<y$, which solves $y=f(y-x(y))$; define $x(0)=0$. For each $y, x(y)$ represents the consumption level which keeps the output level $y$ intact over time. Clearly, $x: \mathbb{R}_{+} \rightarrow \mathbb{R}_{+}$is continuous for $x \geq 0$, and differentiable with

$$
x^{\prime}(y)=\frac{f^{\prime}(y-x(y))-1}{f^{\prime}(y-x(y))}>0 .
$$


For all $y>0$, write

$$
\delta(y):=\frac{1}{f^{\prime}(y-x(y))} .
$$

Then $\delta: \mathbb{R}_{++} \rightarrow(0,1)$ is continuous and non-decreasing in $y$ with $\lim _{y \rightarrow \infty} \delta(y)=1$ by (g.5). Define $\delta(0):=\lim _{y \downarrow 0} \delta(y)$.

Finally, we can define $y^{\infty}(\delta)$, for all $\delta \in(0,1)$, by

$$
y^{\infty}(\delta):=\min \{y \geq 0 \mid \delta(y) \geq \delta\} .
$$

Then $y^{\infty}:(0,1) \rightarrow \mathbb{R}_{+}$is strictly increasing on $[\delta(0), 1]$.

Theorem 1 Consider a Ramsey technology satisfying (g.1)-(g.5). For any $\delta \in$ $(0,1)$ and $y_{0}>0$, there exists a unique SDU optimum ${ }_{0} \mathbf{x}^{*}$.

(i) If $y_{0} \geq y_{\infty}(\delta)$, then ${ }_{0} \mathbf{x}^{*}$ is efficient and egalitarian with $x_{t}^{*}=x\left(y_{0}\right)$ for all $t \geq 0$.

(ii) If $y_{0}<y_{\infty}(\delta)$, then ${ }_{0} \mathbf{x}^{*}$ is efficient and strictly increasing, maximizing $w\left({ }_{0} \mathbf{x}\right)$ over all $y_{0}$-feasible consumption streams and converging to $x\left(y_{\infty}(\delta)\right)$.

For the proof of Theorem 1 we must show that, for any $\delta \in(0,1)$, the set of $y_{0}$-feasible consumption streams, $\mathbb{X}$, is included in $\mathbf{X}_{\delta}$.

Lemma 1 Let $y_{0}>0$ be given. For all $\delta \in(0,1), \mathbb{X} \subseteq \mathbf{X}_{\delta}$.

Proof. Let $y_{0}>0$ and $\delta \in(0,1)$ be given, implying that $(1+\delta) / 2 \delta>1$. While $f(k) / k>1$ for all $k>0$, we have $\lim _{k \rightarrow \infty}[f(k) / k]=1$. Thus, there is $K>y_{0}$ such that $f(k) / k \leq(1+\delta) / 2 \delta$ for all $k \geq K$. This implies that, for all $k \geq K$, we have $\delta f(k) / k \leq(1+\delta) / 2 \equiv \mu<1$.

Define $k_{0}=K$, and $k_{t+1}=f\left(k_{t}\right)$ for $t \geq 0, a_{t}=f\left(k_{t}\right) / k_{t}$ for $t \geq 0$, and $\pi_{t}=\prod_{s=0}^{t} a_{s}$ for $t \geq 0$. Then, for every $y_{0}$-feasible stream, we have $x_{t+1} \leq y_{t+1} \leq$ $f\left(y_{t}-x_{t}\right) \leq f\left(y_{t}\right) \leq f\left(k_{t}\right)=a(t) k(t)=\pi(t) K$, and so:

$$
\delta^{t+1} x_{t+1} \leq \delta^{t+1} \pi_{t} K \leq \mu^{t+1} K \text { for all } t \geq 0 .
$$


Hence, for every $y_{0}$-feasible stream, $\sum_{t=0}^{\infty} \delta^{t} x_{t} \leq K /(1-\mu)<\infty$.

Proof of Theorem 1. Fix $\delta \in(0,1)$ and $y_{0}>0$.

Case (i): $y_{0} \geq y_{\infty}(\delta)$. By the definition of $y_{\infty}(\delta)$ it follows that $\delta\left(y_{0}\right) \geq \delta$. Consider the $y_{0}$-feasible stream ${ }_{0} \mathbf{x}^{*}$ defined by $x_{t}^{*}=x\left(y_{0}\right)$ for all $t \geq 0$, with associated $y_{0}$-feasible program $\left({ }_{0} \mathbf{y}^{e},{ }_{0} \mathbf{k}^{e}\right)$ satisfying, for all $t \geq 0, y_{t}^{e}=y_{0}$ and $k_{t}^{e}=y_{0}-x\left(y_{0}\right)$. Then, $\left({ }_{0} \mathbf{y}^{e},{ }_{0} \mathbf{k}^{e}\right)$ is clearly egalitarian.

Since $y_{0}>0$, we have $f\left(y_{0}-x\left(y_{0}\right)\right)=y_{0}>0$, and so $\left(y_{0}-x\left(y_{0}\right)\right)>0$. Thus, $\theta:=g^{\prime}\left(\left(y_{0}-x\left(y_{0}\right)\right)\right.$ is well-defined and positive. Hence,

$$
f^{\prime}\left(k_{t}^{e}\right)=f^{\prime}\left(y_{0}-x\left(y_{0}\right)\right)=1+\theta>1
$$

for all $t$, so that (16) is satisfied. Further, the price sequence $0 \mathbf{p} \gg 0$ determined by (17), is well-defined, and $\lim _{t \rightarrow \infty} p_{t} k_{t}^{e}=0$. Thus, by the Theorem of Cass and Yaari $\left(1971\right.$, p. 337), $\left({ }_{0} \mathbf{y}^{e},{ }_{0} \mathbf{k}^{e}\right)$ is efficient. By the definition of the function $\delta$,

$$
f^{\prime}\left(k_{t}^{e}\right)=f^{\prime}\left(y_{0}-x\left(y_{0}\right)\right)=\frac{1}{\delta\left(y_{0}\right)} \leq \frac{1}{\delta}
$$

for all $t$, so that (15) is also satisfied. It follows now from Proposition 3 and Lemma 1 that ${ }_{0} \mathbf{x}^{*}$ is the unique SDU optimum.

Case (ii): $y_{0}<y_{\infty}(\delta)$. By the definition of $y_{\infty}(\delta)$ it follows that $\delta\left(y_{0}\right)<\delta$. It is well-known (see Beals and Koopmans, 1969) that there exists $y_{0}$-feasible program $\left({ }_{0} \mathbf{y}^{*},{ }_{0} \mathbf{k}^{*}\right)$ satisfying

$$
\lim _{t \rightarrow \infty} y_{t}^{*}=y_{\infty}(\delta) \quad \text { and } \quad \lim _{t \rightarrow \infty} k_{t}^{*}=y_{\infty}(\delta)-x\left(y_{\infty}(\delta)\right)
$$

which is efficient, and which has associated with it a $y_{0}$-feasible stream ${ }_{0} \mathbf{x}^{*} \in \mathbf{X}_{\varphi}$. Furthermore, ${ }_{0} \mathbf{x}^{*}$ is strictly increasing and uniquely maximizes $w\left({ }_{0} \mathbf{x}\right)$ over all $y_{0}-$ feasible programs $\left({ }_{0} \mathbf{y},{ }_{0} \mathbf{k}\right)$ with associated $y_{0}$-feasible stream ${ }_{0} \mathbf{x}$. Hence, if ${ }_{0} \mathbf{x}$ is a $y_{0}$-feasible stream distinct from ${ }_{0} \mathbf{x}^{*}$ and $W: \mathbf{X}_{\delta} \rightarrow \mathbb{R}$ satisfies (W.1)-(W.4), then Proposition 1 and Lemma 1 imply

$$
W\left({ }_{0} \mathbf{x}^{*}\right)=w\left({ }_{0} \mathbf{x}^{*}\right)>w\left({ }_{0} \mathbf{x}\right) \geq W\left({ }_{0} \mathbf{x}\right),
$$

thereby establishing that ${ }_{0} \mathrm{x}^{*}$ is the unique SDU optimum. 
Theorem 1 means that the unique SDU optimal stream coincides the DU optimum stream with increasing consumption if there is a small initial capital stock (so that net capital productivity is high), while it coincides with the egalitarian and efficient stream with a large initial capital stock.

\section{Dasgupta-Heal-Solow technologies}

A Dasgupta-Heal-Solow technology (DHS) (see Dasgupta and Heal, 1974, 1979; Solow, 1974) is determined by a stationary production function $G: \mathbb{R}_{+}^{3} \rightarrow \mathbb{R}$ that satisfies

$G$ is concave, non-decreasing, homogeneous of degree one, and continuous for $(k, r, \ell) \in \mathbb{R}_{+}^{3}$,

$G$ is twice continuously differentiable and satisfies $\left(G_{k}, G_{r}, G_{\ell}\right) \gg 0$ for $(k, r, \ell) \in \mathbb{R}_{++}^{3}$.

$G(k, 0, \ell)=0=G(0, r, \ell)$

Given any $\left(k^{\prime}, r^{\prime}\right) \gg 0$, there is $\eta^{\prime}>0$ such that for all $(k, r)$

satisfying $k \geq k^{\prime}, 0<r \leq r^{\prime},\left[r G_{r}(k, r, 1)\right] / G_{\ell}(k, r, 1) \geq \eta^{\prime}$.

(G.3) states that both capital input $k$ and resource use $r$ are essential in production.

(G.4) requires that the ratio of the share of the resource in net output to the share of labor in net output is bounded away from zero (when labor is fixed at unit level).

The labor force is assumed to be stationary and normalized to 1. The gross output function $F$, is defined by $F(k, r)=G(k, r, 1)+k$ for all $(k, r) \geq 0$, and is assumed to satisfy

$$
\begin{aligned}
& F \text { is strictly concave in }(k, r) \text { on } \mathbb{R}_{+}^{2} \\
& F_{k r} \geq 0 \text { for }(k, r) \in \mathbb{R}_{++}^{2}
\end{aligned}
$$

where (F.2) is used to ensure (19) of Lemma 3 below. 
Let $y$ denote gross output and $m$ the total resource stock. The production possibilities are described by the stationary transformation set $\mathcal{T}$ given by

$$
\mathcal{T}=\left\{\left[(k, m),\left(y, m^{\prime}\right)\right] \mid 0 \leq y \leq F(k, r) ; 0 \leq r=m-m^{\prime} \leq m\right\}
$$

A program $\left({ }_{t} \mathbf{y},{ }_{t} \mathbf{m},{ }_{t} \mathbf{k}\right)$ is $\left(y_{t}, m_{t}\right)$-feasible if there exist ${ }_{t} \mathbf{k},{ }_{t+1} \mathbf{y}$ and ${ }_{t+1} \mathbf{m}$ satisfying

$$
0 \leq k_{\tau} \leq y_{\tau} \quad \text { and } \quad\left[\left(k_{\tau}, m_{\tau}\right),\left(y_{\tau+1}, m_{\tau+1}\right)\right] \in \mathcal{T} \quad \text { for all } \tau \geq t
$$

The consumption ${ }_{t} \mathbf{x}$ associated with a $\left(y_{t}, m_{t}\right)$-feasible program $\left({ }_{t} \mathbf{y},{ }_{t} \mathbf{m},{ }_{t} \mathbf{k}\right)$ is defined by $x_{\tau}=y_{\tau}-k_{\tau}$ for all $\tau \geq t$. A $\left(y_{t}, m_{t}\right)$-feasible program $\left({ }_{t} \mathbf{y},{ }_{t} \mathbf{m},{ }_{t} \mathbf{k}\right)$ is called egalitarian if the consumption stream ${ }_{t} \mathbf{X}$ associated with it is egalitarian. A $\left(y_{t}, m_{t}\right)$-feasible program $\left({ }_{t} \overline{\mathbf{y}},{ }_{t} \overline{\mathbf{m}},{ }_{t} \overline{\mathbf{k}}\right)$ is $\left(y_{t}, m_{t}\right)$-efficient if there is no $\left(y_{t}, m_{t}\right)$ feasible program $\left({ }_{t} \mathbf{y},{ }_{t} \mathbf{m},{ }_{t} \mathbf{k}\right)$ satisfying $x_{\tau} \geq \bar{x}_{\tau}$ for all $\tau \geq t$, with strict inequality for some $\tau \geq t$.

The set $\mathbb{X} \subset \mathbb{R}_{+}^{\mathbb{Z}_{+}}$of feasible consumption streams, introduced in Section 3, can be described for DHS technologies by:

$$
\begin{aligned}
\mathbb{X}=\left\{{ }_{0} \mathbf{X} \in \mathbb{R}_{+}^{\mathbb{Z}_{+}}\right. & \mid{ }_{0} \mathbf{x} \text { is a consumption stream associated } \\
& \text { with a } \left.\left(y_{0}, m_{0}\right) \text {-feasible program }\left({ }_{0} \mathbf{y},{ }_{0} \mathbf{m},{ }_{0} \mathbf{k}\right)\right\}
\end{aligned}
$$

Lemma 2 Let $\left(y_{0}, m_{0}\right) \gg 0$ be given. For all $\delta \in(0,1), \mathbb{X} \subseteq \mathbf{X}_{\delta}$.

Proof. Let $\left(y_{0}, m_{0}\right)>>0$ and $\delta \in(0,1)$ be given. Define $f(k)=F\left(k, m_{0}, 1\right)+k$ for $k \geq 0$. Then $f(k) / k>1$ for all $k>0$, while we have $\lim _{k \rightarrow \infty}[f(k) / k]=1$. Therefore, the argument given in the proof of Lemma 1 applies here as well.

Assumptions (G.1)-(G.4) and (F.1)-(F.2) do not ensure the existence of an egalitarian stream with positive consumption. We concentrate on those technologies satisfying (G.1)-(G.4) and (F.1)-(F.2) which do. That is, we assume:

There exists from any $(y, m) \gg 0$

an egalitarian positive consumption stream.

Cass and Mitra (1991) give a necessary and sufficient condition on $F$ for (E) to hold. 
Lemma 3 Consider a DHS technology satisfying (G.1)-(G.4), (F.1)-(F.2) and (E). For any $\left(y_{0}, m_{0}\right) \gg 0$, there exists a unique $\left(y_{0}, m_{0}\right)$-feasible program $\left({ }_{0} \mathbf{y}^{e},{ }_{0} \mathbf{m}^{e},{ }_{0} \mathbf{k}^{e}\right)$ such that the associated $\left(y_{0}, m_{0}\right)$-feasible stream ${ }_{0} \mathbf{x}^{e} \gg 0$ is efficient and egalitarian. Furthermore, the price sequence ${ }_{0} \mathbf{p} \gg 0$ determined by

$$
p_{0}=1 \quad \text { and } \quad p_{t+1} F_{k}\left(k_{t}^{e}, m_{t}^{e}-m_{t+1}^{e}\right)=p_{t} \quad \text { for all } t \geq 0
$$

satisfies:

$$
0<\frac{p_{t}}{p_{t-1}}<\frac{p_{t+1}}{p_{t}} \text { for all } t>1
$$

and:

$$
\infty>\sum_{t=0}^{\infty} p_{t} x_{t}^{e} \geq \sum_{t=0}^{\infty} p_{t} x_{t}
$$

holds for every $\left(y_{0}, m_{0}\right)$-feasible stream ${ }_{0} \mathbf{x}$.

Proof. The existence of an efficient and egalitarian $\left(y_{0}, m_{0}\right)$-feasible program $\left({ }_{0} \mathbf{y}^{e},{ }_{0} \mathbf{m}^{e},{ }_{0} \mathbf{k}^{e}\right)$, such that the associated $\left(y_{0}, m_{0}\right)$-feasible consumption stream ${ }_{0} \mathbf{x}^{e}$ $\gg$ 0, follows from Dasgupta and Mitra (1983, Proposition 5); uniqueness follows from (F.1). Property (19) of the price sequence ${ }_{0} \mathbf{p}$ follows from Asheim (1988, Lemma 3 and Proposition 1). Property (20) of maximization of the present value of the consumption stream at ${ }_{0} \mathbf{x}^{e}$ follows from Dasgupta and Mitra (1983, Theorem $1)$.

For each $\left(y_{0}, m_{0}\right) \gg 0$, consider the unique $\left(y_{0}, m_{0}\right)$-feasible program $\left({ }_{0} \mathbf{y}^{e},{ }_{0} \mathbf{m}^{e}\right.$, $\left.{ }_{0} \mathbf{k}^{e}\right)$, guaranteed by Lemma 3 , such that the associated $\left(y_{0}, m_{0}\right)$-feasible consumption stream ${ }_{0} \mathbf{x}^{e} \gg 0$ is efficient and egalitarian. Furthermore, let ${ }_{0} \mathbf{p} \gg 0$ be the associated price sequence determined by (18). By (20), we have $\sum_{t=0}^{\infty} p_{t}<\infty$. For each $\left(y_{0}, m_{0}\right) \gg 0$, we can then define:

$$
\delta^{0}\left(y_{0}, m_{0}\right):=\left(\frac{p_{1}}{p_{0}}\right) \quad \text { and } \quad \delta^{\infty}\left(y_{0}, m_{0}\right):=\left[\frac{\sum_{t=1}^{\infty} p_{t}}{\sum_{t=0}^{\infty} p_{t}}\right] .
$$

For each $\left(y_{0}, m_{0}\right) \gg 0$, we refer to $\delta^{0}\left(y_{0}, m_{0}\right)$ as the short-run discount factor and to $\delta^{\infty}\left(y_{0}, m_{0}\right)$ as the long-run discount factor at time 0 supporting the efficient and egalitarian $\left(y_{0}, m_{0}\right)$-feasible program $\left({ }_{0} \mathbf{y}^{e},{ }_{0} \mathbf{m}^{e},{ }_{0} \mathbf{k}^{e}\right)$. 
When the short-run discount factor is at least as large as $\delta$, the efficient egalitarian program described in Lemma 3 is the unique SDU optimum, as the following proposition shows.

Proposition 4 Consider a DHS technology satisfying (G.1)-(G.4), (F.1)-(F.2) and (E). If $\left(y_{0}, m_{0}\right) \gg 0$ satisfies $\delta^{0}\left(y_{0}, m_{0}\right) \geq \delta$, then the efficient and egalitarian $\left(y_{0}, m_{0}\right)$-feasible stream ${ }_{0} \mathbf{x}^{e} \gg 0$ is the unique $S D U$ optimum.

Proof. It follows from Lemma 3 that ${ }_{0} \mathbf{p} \gg 0$, the price sequence determined by (18) and supporting the unique $\left(y_{0}, m_{0}\right)$-feasible program $\left({ }_{0} \mathbf{y}^{e},{ }_{0} \mathbf{m}^{e},{ }_{0} \mathbf{k}^{e}\right)$, satisfies (2) and (3). Hence, by Proposition $2,{ }_{0} \mathbf{x}^{e}$ is the unique SDU optimum.

When the short-run discount factor is smaller than $\delta$, the description of an SDU optimum is more involved. To carry out the analysis, we have to compare the longrun discount factor with $\delta$. For this purpose, a preliminary result comparing the short-run and the long-run discount factors is useful.

Lemma 4 Consider a DHS technology satisfying (G.1)-(G.4), (F.1)-(F.2) and (E). For all $\left(y_{0}, m_{0}\right) \gg 0, \delta^{0}\left(y_{0}, m_{0}\right)<\delta^{\infty}\left(y_{0}, m_{0}\right)$.

Proof. The price sequence ${ }_{0} \mathbf{p} \gg 0$, determined by (18), and supporting the unique $\left(y_{0}, m_{0}\right)$-feasible program $\left({ }_{0} \mathbf{y}^{e},{ }_{0} \mathbf{m}^{e},{ }_{0} \mathbf{k}^{e}\right)$ obtained in Lemma 3 , satisfies (19). Denote $\left(p_{1} / p_{0}\right)$ by $\rho$. Then, by using (19), we have $\theta>0$, such that $\left(p_{t+1} / p_{t}\right)>$ $\rho+\theta$ for all $t \geq 1$. Let $T \geq 2$ be given. Then, for $t \in\{1, \ldots, T\}$, we have

$$
p_{t+1}>\rho p_{t}+\theta p_{t} .
$$

Adding up the inequalities in (21) from $t=1$ to $t=T$, we get:

$$
p_{2}+p_{3}+\cdots+p_{T+1}>\rho\left(p_{1}+p_{2}+\cdots+p_{T}\right)+\theta p_{1} .
$$

Adding the trivial equality $p_{1}=\rho p_{0}$ to (22), we obtain:

$$
p_{1}+p_{2}+p_{3}+\cdots+p_{T+1}>\rho\left(p_{0}+p_{1}+p_{2}+\cdots+p_{T}\right)+\theta p_{1} .
$$


This yields

$$
\left[\frac{p_{1}+p_{2}+p_{3}+\cdots+p_{T+1}}{p_{0}+p_{1}+p_{2}+\cdots+p_{T}}\right]>\rho+\left[\frac{\theta p_{1}}{p_{0}+p_{1}+p_{2}+\cdots+p_{T}}\right] \geq \rho+\left[\frac{\theta p_{1}}{\sigma}\right]
$$

where $\sigma=\sum_{t=0}^{\infty} p_{t}$. Letting $T \rightarrow \infty$ in (23), we get:

$$
\delta^{\infty}\left(y_{0}, m_{0}\right) \geq \rho+\left[\frac{\theta p_{1}}{\sigma}\right]>\rho=\delta^{0}\left(y_{0}, m_{0}\right),
$$

which is the desired result.

To proceed further, we note that even when the short-run discount factor is initially smaller than $\delta$ for a $\left(y_{0}, m_{0}\right)$-feasible program, the short-run discount factor becomes at least as large as $\delta$ after a finite time period, provided the consumption stream on such a program is bounded away from zero.

Lemma 5 Consider a DHS technology satisfying (G.1)-(G.4), (F.1)-(F.2) and (E). Let $\left(y_{0}, m_{0}\right) \gg 0$ and $\delta \in(0,1)$. If a $\left(y_{0}, m_{0}\right)$-feasible program $\left({ }_{0} \mathbf{y},{ }_{0} \mathbf{m},{ }_{0} \mathbf{k}\right)$ has an associated $\left(y_{0}, m_{0}\right)$-feasible stream ${ }_{0} \mathbf{x} \gg 0$ with $\liminf _{T \rightarrow \infty} w\left({ }_{T} \mathbf{x}\right)>U(0)$, then there exists $\tau \geq 0$ such that $\delta \leq \delta^{0}\left(y_{\tau}, m_{\tau}\right)$.

Proof. Assume that $\left({ }_{0} \mathbf{y},{ }_{0} \mathbf{m},{ }_{0} \mathbf{k}\right)$ is a $\left(y_{0}, m_{0}\right)$-feasible program where the associated $\left(y_{0}, m_{0}\right)$-feasible stream ${ }_{0} \mathbf{x} \gg 0$ satisfies $\liminf _{T \rightarrow \infty} w\left({ }_{T} \mathbf{x}\right)>U(0)$. By (G.1) and (G.3), there exists $\tilde{k} \geq 1$ satisfying $F\left(1, m_{0} / \tilde{k}\right) \leq 1 / \delta$. Note that $k_{T} \rightarrow \infty$ as $T \rightarrow \infty$ and $m_{t}>0$ for all $t \geq 0$ (since otherwise $\liminf _{T \rightarrow \infty} w\left(_{T} \mathbf{x}\right)=U(0)$, contradicting the hypothesis of the lemma). Choose a time $\tau$ such that $k_{\tau} \geq \tilde{k} \geq$ 1. Consider the efficient and egalitarian $\left(y_{\tau}, m_{\tau}\right)$-feasible program $\left({ }_{\tau} \mathbf{y}^{e},{ }_{\tau} \mathbf{m}^{e},{ }_{\tau} \mathbf{k}^{e}\right)$, with supporting price sequence ${ }_{\tau}$ p. By Lemma 3 and (G.1)-(G.3),

$$
\begin{aligned}
{\left[\frac{1}{\delta^{0}\left(y_{\tau}, m_{\tau}\right)}\right] } & =\left[\frac{p_{\tau}}{p_{\tau+1}}\right]=F_{k}\left(k_{\tau}, m_{\tau}-m_{\tau+1}^{e}\right) \leq F\left(k_{\tau}, m_{\tau}-m_{\tau+1}^{e}\right) / k_{\tau} \\
& \leq F\left(1,\left(m_{\tau}-m_{\tau+1}^{e}\right) / k_{\tau}\right)<F\left(1, m_{0} / \tilde{k}\right) \leq \frac{1}{\delta},
\end{aligned}
$$

thereby establishing that there is a finite time $\tau$ such that $\delta^{0}\left(y_{\tau}, m_{\tau}\right) \geq \delta$.

It follows from Proposition 1 that SDU welfare is non-decreasing: $W\left({ }_{t} \mathbf{x}\right) \leq$ $W\left({ }_{t+1} \mathbf{x}\right)$ for all $t \in \mathbb{Z}_{+}$. Still, $x_{t}$ may contribute to $W\left({ }_{t} \mathbf{x}\right)$ even if $x_{t}>x_{t+1}$, provided 
that $U\left(x_{t+1}\right)<W\left({ }_{t+2} \mathbf{x}\right)$. Indeed, it is straightforward to show that streams that are not non-decreasing can be SDU optimum in non-stationary technologies. However, SDU optimum streams in DHS technologies (as in Ramsey technologies) will in fact be streams maximizing $w\left({ }_{0} \mathbf{x}\right)$ subject to the constraint that $x_{t} \leq x_{t+1}$ for all $t \in \mathbb{Z}_{+}$. Such streams have been analyzed in discrete time by Asheim (1988) and in continuous time by Pezzey (1994). This motivates the following lemma.

Lemma 6 Consider a DHS technology satisfying (G.1)-(G.4), (F.1)-(F.2) and (E). For any $\left(y_{0}, m_{0}\right) \gg 0$, there exists a $\left(y_{0}, m_{0}\right)$-feasible program $\left({ }_{0} \mathbf{y}^{*},{ }_{0} \mathbf{m}^{*},{ }_{0} \mathbf{k}^{*}\right)$ with the property that the associated $\left(y_{0}, m_{0}\right)$-feasible stream ${ }_{0} \mathbf{x}^{*} \gg 0$ maximizes $w\left({ }_{0} \mathbf{x}\right)$ over all $\left(y_{0}, m_{0}\right)$-feasible and non-decreasing consumption streams ${ }_{0} \mathbf{x}$. Furthermore,

(i) $\left({ }_{0} \mathbf{y}^{*}, \mathbf{m}^{*},{ }_{0} \mathbf{k}^{*}\right)$ is unique and time-consistent (for all $t \geq 0,{ }_{t} \mathbf{x}^{*}$ maximizes $w\left({ }_{t} \mathbf{x}\right)$ over all $\left(y_{t}^{*}, m_{t}^{*}\right)$-feasible and non-decreasing consumption streams $\left.{ }_{t} \mathbf{x}\right)$,

(ii) ${ }_{0} \mathbf{x}^{*} \in \mathbf{X}_{\varphi}$; in particular, there is a $\tau \geq 0$ such that

$$
x_{0}^{*}<\cdots<x_{\tau-1}^{*}<x_{\tau}^{*}=x_{\tau+1}^{*}=\cdots,
$$

where $\tau>0$ if $\delta^{\infty}\left(y_{0}, m_{0}\right)<\delta$, and $\tau=0$ if $\delta^{\infty}\left(y_{0}, m_{0}\right) \geq \delta$.

(iii) There is a $\mu$ such that if ${ }_{0} \mathbf{x}$ is an arbitrary $\left(y_{0}, m_{0}\right)$-feasible stream, with ${ }_{1} \mathbf{x}$ non-decreasing, then

$$
\delta \cdot\left[w\left({ }_{1} \mathbf{x}\right)-w\left({ }_{1} \mathbf{x}^{*}\right)\right] \leq \mu \cdot\left[U\left(x_{0}^{*}\right)-U\left(x_{0}\right)\right]
$$

where $\mu=1$ if $\delta^{\infty}\left(y_{0}, m_{0}\right)<\delta$ and $0<\mu \leq 1$ if $\delta^{\infty}\left(y_{0}, m_{0}\right) \geq \delta$, and where (24) is strict if the associated $\left(y_{0}, m_{0}\right)$-feasible program $\left({ }_{0} \mathbf{y},{ }_{0} \mathbf{m},{ }_{0} \mathbf{k}\right)$ is distinct from $\left({ }_{0} \mathbf{y}^{*},{ }_{0} \mathbf{m}^{*},{ }_{0} \mathbf{k}^{*}\right)$.

Proof. Existence follows from Asheim (1988, Proposition 2, sufficiency part).

Parts (i) and (ii) follow from Asheim (1988, Lemma 4 (a) and (c)). That ${ }_{0} \mathbf{x}^{*}$ is egalitarian if $\delta^{\infty}\left(y_{0}, m_{0}\right) \geq \delta$ follows from Asheim (1988, Lemma 4 (b)). The proof of Asheim (1988, Lemma 4) implies the two-phase structure of ${ }_{0} \mathbf{x}^{*}$, stated in part (ii). Finally, Lemma 5 of this paper establishes that $\tau$ of part (ii) is finite. 
Lemma 6 entails that there exist unique policy functions $k^{*}$ and $m^{*}$ such that, for all $\left(y_{0}, m_{0}\right) \gg 0, k_{0}^{*}=k^{*}\left(y_{0}, m_{0}\right), m_{1}^{*}=m^{*}\left(y_{0}, m_{0}\right)$ and $y_{1}^{*}=F\left(k^{*}\left(y_{0}, m_{0}\right), m_{0}-\right.$ $\left.m^{*}\left(y_{0}, m_{0}\right)\right)$, where $\left({ }_{0} \mathbf{y}^{*},{ }_{0} \mathbf{m}^{*},{ }_{0} \mathbf{k}^{*}\right)$ is the unique $\left(y_{0}, m_{0}\right)$-feasible program with the property that the associated $\left(y_{0}, m_{0}\right)$-feasible stream ${ }_{0} \mathbf{x}^{*} \gg 0$ maximizes $w\left({ }_{0} \mathbf{x}\right)$ over all $\left(y_{0}, m_{0}\right)$-feasible and non-decreasing consumption streams ${ }_{0} \mathbf{x}$.

Theorem 2 Consider a DHS technology satisfying (G.1)-(G.4), (F.1)-(F.2) and (E). For any $\delta \in(0,1)$ and $\left(y_{0}, m_{0}\right) \gg 0$, let ${ }_{0} \mathbf{x}^{*} \gg 0$ denote the efficient $\left(y_{0}, m_{0}\right)$ feasible stream maximizing $w\left({ }_{0} \mathbf{x}\right)$ over all $\left(y_{0}, m_{0}\right)$-feasible and non-decreasing consumption streams ${ }_{0} \mathbf{x}$. Then ${ }_{0} \mathbf{x}^{*}$ is the unique SDU optimum. The stream has an eventual egalitarian phase, preceded by a phase with increasing consumption if and only if $\delta^{\infty}\left(y_{0}, m_{0}\right)<\delta$.

Proof. Suppose that ${ }_{0} \mathbf{x}$ is a $\left(y_{0}, m_{0}\right)$-feasible stream distinct from ${ }_{0} \mathbf{x}^{*}$ such that $W\left({ }_{0} \mathbf{x}\right) \geq W\left({ }_{0} \mathbf{x}^{*}\right)$ for some $W: \mathbf{X}_{\delta} \rightarrow \mathbb{R}$ satisfying (W.1)-(W.4). Let $\left({ }_{0} \mathbf{y},{ }_{0} \mathbf{m},{ }_{0} \mathbf{k}\right)$ be the $\left(y_{0}, m_{0}\right)$-feasible program associated with ${ }_{0} \mathbf{x}$. Since, by Propositions 8 and 1(ii) (recalling that ${ }_{0} \mathbf{x}^{*} \in \mathbf{X}_{\varphi}$ is non-decreasing),

$$
\bar{W}\left({ }_{0} \mathbf{x}\right) \geq W\left({ }_{0} \mathbf{x}\right) \geq W\left({ }_{0} \mathbf{x}^{*}\right)=w\left({ }_{0} \mathbf{x}^{*}\right)>U(0),
$$

it follows from $(\overline{\mathrm{W}})$ that $\liminf _{T \rightarrow \infty} w\left({ }_{T} \mathbf{x}\right)>U(0)$. Hence, by Lemma 5 , there exists $\tilde{\tau} \geq 0$ such that $\delta^{0}\left(y_{\tilde{\tau}}, m_{\tilde{\tau}}\right) \geq \delta$. By Proposition 4 and (W.1), we may assume, without loss of generality, that $\left(\tilde{\tau} \mathbf{y}, \tilde{\tau} \mathbf{m},{ }_{\tilde{\tau}} \mathbf{k}\right)=\left({ }_{\tilde{\tau}} \mathbf{y}^{e}, \tilde{\tau} \mathbf{m}^{e},{ }_{\tilde{\tau}} \mathbf{k}^{e}\right)$, where $\left({ }_{\tilde{\tau}} \mathbf{y}^{e},{ }_{\tilde{\tau}} \mathbf{m}^{e},{ }_{\tilde{\tau}} \mathbf{k}^{e}\right)$ is the unique efficient and egalitarian $\left(y_{\tilde{\tau}}, m_{\tilde{\tau}}\right)$-feasible program. By Lemmas 4 and 6(i)\&(ii), $k_{t}=k^{*}\left(y_{t}, m_{t}\right), m_{t+1}=m^{*}\left(y_{t}, m_{t}\right)$ and $y_{t+1}=F\left(k^{*}\left(y_{t}, m_{t}\right), m_{t}-\right.$ $\left.m^{*}\left(y_{t}, m_{t}\right)\right)$ for all $t \geq \tilde{\tau}$. Since ${ }_{0} \mathbf{x}$ is distinct from ${ }_{0} \mathbf{x}^{*}$, we may define $\tau \geq 0$ by

$$
\begin{aligned}
\tau:=\max \left\{t \geq 0 \mid k_{t} \neq k^{*}\left(y_{t}, m_{t}\right) \text { or } m_{t+1} \neq m^{*}\left(y_{t}, m_{t}\right)\right. \\
\text { or } \left.y_{t+1} \neq F\left(k^{*}\left(y_{t}, m_{t}\right), m_{t}-m^{*}\left(y_{t}, m_{t}\right)\right)\right\} .
\end{aligned}
$$

Let $\left({ }_{\tau} \mathbf{y}^{*},{ }_{\tau} \mathbf{m}^{*},{ }_{\tau} \mathbf{k}^{*}\right)$ be the unique $\left(y_{\tau}, m_{\tau}\right)$-feasible program with the property that the associated $\left(y_{\tau}, m_{\tau}\right)$-feasible stream ${ }_{\tau} \mathbf{x}^{*} \gg 0$ maximizes $w\left({ }_{\tau} \mathbf{x}^{\prime}\right)$ over all 
$\left(y_{\tau}, m_{\tau}\right)$-feasible and non-decreasing consumption streams ${ }_{\tau} \mathbf{x}^{\prime}$. By the definition of $\tau,\left({ }_{\tau} \mathbf{y},{ }_{\tau} \mathbf{m},{ }_{\tau} \mathbf{k}\right)$ is distinct from $\left({ }_{\tau} \mathbf{y}^{*},{ }_{\tau} \mathbf{m}^{*},{ }_{\tau} \mathbf{k}^{*}\right)$ with ${ }_{\tau+1} \mathbf{x}$ being non-decreasing. By (W.1), we may assume, without loss of generality, that $W\left({ }_{\tau} \mathbf{x}\right) \geq W\left({ }_{\tau} \mathbf{x}^{*}\right) \geq 0$. By Lemma 6(iii),

$$
W\left({ }_{\tau} \mathbf{x}\right)-W\left({ }_{\tau} \mathbf{x}^{*}\right) \leq w\left({ }_{\tau} \mathbf{x}\right)-w\left({ }_{\tau} \mathbf{x}^{*}\right)<(1-\mu) \cdot\left[U\left(x_{\tau}\right)-U\left(x_{\tau}^{*}\right)\right]
$$

where $\mu=1$ if $\delta^{\infty}\left(y_{\tau}, m_{\tau}\right)<\delta$ and $0<\mu \leq 1$ if $\delta^{\infty}\left(y_{\tau}, m_{\tau}\right) \geq \delta$, since $W\left({ }_{\tau} \mathbf{x}\right) \leq$ $w\left({ }_{\tau} \mathbf{x}\right)$ by Proposition $1(\mathrm{i})$ and $W\left({ }_{\tau} \mathbf{x}^{*}\right)=w\left({ }_{\tau} \mathbf{x}^{*}\right)$ by Proposition 1(ii), keeping in mind that ${ }_{\tau} \mathbf{x}^{*} \in \mathbf{X}_{\varphi}$ is non-decreasing.

Case 1: $\delta^{\infty}\left(y_{\tau}, m_{\tau}\right)<\delta$. Then, by Lemma 6(iii), $\mu=1$, implying by (25) that, $W\left({ }_{\tau} \mathbf{x}\right)-W\left({ }_{\tau} \mathbf{x}^{*}\right)<0$. This contradicts $W\left({ }_{\tau} \mathbf{x}\right) \geq W\left({ }_{\tau} \mathbf{x}^{*}\right)$.

Case 2: $\delta^{\infty}\left(y_{\tau}, m_{\tau}\right) \geq \delta$. By Lemma 6(ii), ${ }_{\tau} \mathbf{x}^{*}$ is egalitarian, implying that $W\left({ }_{\tau} \mathbf{x}^{*}\right)=w\left({ }_{\tau} \mathbf{x}^{*}\right)=w\left({ }_{\tau+1} \mathbf{x}^{*}\right)$. Furthermore, it follows from Proposition 1(i) that $W\left({ }_{\tau} \mathbf{x}\right) \leq W\left({ }_{\tau+1} \mathbf{x}\right) \leq w\left({ }_{\tau+1} \mathbf{x}^{*}\right)$. Hence, by Lemma 6(iii),

$$
W\left({ }_{\tau} \mathbf{x}\right)-W\left({ }_{\tau} \mathbf{x}^{*}\right) \leq w\left({ }_{\tau+1} \mathbf{x}\right)-w\left({ }_{\tau+1} \mathbf{x}^{*}\right)<\frac{\mu \cdot\left[U\left(x_{\tau}^{*}\right)-U\left(x_{\tau}\right)\right]}{\delta},
$$

where $0<\mu \leq 1$. If $\mu=1$, then (25) contradicts $W\left({ }_{\tau} \mathbf{x}\right) \geq W\left({ }_{\tau} \mathbf{x}^{*}\right)$. If $0<\mu<1$, then (25) and (26) are incompatible.

In either case, we contradict that there exists a $\left(y_{0}, m_{0}\right)$-feasible stream ${ }_{0} \mathbf{x}$ distinct from ${ }_{0} \mathbf{x}^{*}$ such that $W\left({ }_{0} \mathbf{x}\right) \geq W\left({ }_{0} \mathbf{x}^{*}\right) \geq 0$.

It follows from Lemma 6 (ii) that ${ }_{0} \mathbf{x}^{*}$ has an eventual egalitarian phase, preceded by a phase with increasing consumption if and only if $\delta^{\infty}\left(y_{0}, m_{0}\right)<\delta$.

\section{Concluding remarks}

The DHS model of capital accumulation and resource depletion gives rise to interesting distributional conflicts. On the one hand, when applied to DHS technologies DU undermines the interests of the generations in the far future by forcing consumption to approach zero as time goes to infinity. On the other hand, criteria like classical utilitarianism and leximin that treat generations equally by satisfying 
Finite Anonymity, and thus are not numerically representable, lead to consequences that may not be compelling: classical utilitarianism leads to unbounded inequality by giving rise to unlimited growth, while leximin does not allow for any trade-off between the interests of different generations, meaning that poverty may be perpetuated if the economy has a small initial endowment of stocks (cf. Solow, 1974).

In this paper we have applied sustainable discounted utilitarianism (SDU) to DHS technologies and showed that the application of this criterion resolves in an appealing way the distributional conflicts that arise in this class of technologies:

(1) It allows for growth and development initially when the economy is highly productive.

(2) It leads to an efficient and egalitarian stream eventually when resource depletion and capital accumulation have reduced net capital productivity. By thus preventing consumption to approach zero, it respects the interests of future generations. By not yielding unlimited growth, it ensures bounded inequality.

We have also applied SDU to the usual one-sector model of economic growth (Ramsey technologies). If, in this setting, there is a small initial capital stock (so that net capital productivity is high), then the criterion leads to the DU optimum stream with increasing consumption. With a large initial capital stock, however, the criterion gives rise to an efficient and egalitarian stream.

SDU trades off present and future consumption if and only if the present is worse off than the future, while it gives priority to the interests of future generations otherwise. In the two classes of technologies considered, this property of SDU entails that the criterion allows for economic development when productivity is high without leading to inequitable outcomes. A dilemma posed by Epstein (1986) (that an economy has to choose between development and equity; it cannot have both) is thereby apparently resolved. Moreover, in both classes of technologies, we obtain intergenerational streams in congruence with a view expressed by Dasgupta and Heal (1979, p. 311) and Rawls (1999, pp. 251-255) (see also Gaspart and Gosseries, 
2007) that trading present consumption for future consumption is more appropriate for poorer societies, while equality considerations should dominate for richer ones.

The axiomatic underpinnings of SDU is not the main focus of this paper, even though, in the appendix, we show that SDU satisfies all the axioms characterizing sustainable recursive SWFs, a concept analyzed in our companion paper (Asheim, Mitra and Tungodden, 2008). Rather, the investigation of this paper seeks to demonstrate convincingly that SDU is an applicable criterion yielding consequences that might appeal to our ethical intuition.

\section{A Appendix}

\section{A.1 Existence of a Sustainable Discounted Utilitarian SWF}

We are given $\delta \in(0,1)$ and $U: \mathbb{R}_{+} \rightarrow \mathbb{R}$ satisfying (U.1). We want to establish existence of a function $W: \mathbf{X}_{\delta} \rightarrow \mathbb{R}$ satisfying (W.1)-(W.4). To this end, we first establish a basic monotonicity property, and then use that with a backward iteration device to define a function $\bar{W}$ with these properties.

Write $Z:=[U(0), \infty)$. For $(a, b) \in Z \times Z$, define:

$$
f(a, b)=\min \{(1-\delta) a+\delta b, b\} .
$$

Note that $f$ is a well-defined function from $Z^{2}$ to $Z$, and furthermore:

$$
f(a, b) \leq(1-\delta) a+\delta b \quad \text { and } \quad f(a, b) \leq b \quad \text { for all }(a, b) \in Z^{2} .
$$

Lemma 7 Suppose $(a, b) \in Z^{2}$ and $\left(a^{\prime}, b^{\prime}\right) \in Z^{2}$, with $\left(a^{\prime}, b^{\prime}\right) \leq(a, b)$. Then

$$
f\left(a^{\prime}, b^{\prime}\right) \leq f(a, b) .
$$

Further, if $b^{\prime}<b$, then

$$
f\left(a^{\prime}, b^{\prime}\right)<f(a, b) .
$$

Proof. We split the proof into two cases: (i) $a=a^{\prime}$; (ii) $a<a^{\prime}$.

In case (i), since (A2) is clearly true when $b^{\prime}=b$, we need to consider only the case where $b^{\prime}<b$. In this case, we will establish that $\left(\mathrm{A} 2^{\prime}\right)$ holds, which will establish both statements 
in the Lemma. Suppose, contrary to $\left(\mathrm{A}^{\prime}\right)$, that $c^{\prime}:=f\left(a, b^{\prime}\right) \geq f(a, b)=: c$. Then, using (A1), we have

$$
c \leq c^{\prime} \leq b^{\prime}<b .
$$

Since $c<b$, we can infer from (f) that:

$$
c=(1-\delta) a+\delta b
$$

and that $a<b$. Then, using (A3) and (A4), we have:

$$
c^{\prime} \geq c=(1-\delta) a+\delta b>(1-\delta) a+\delta b^{\prime}
$$

Thus, by (f), we must have:

$$
c^{\prime}=b^{\prime} \text { and } a>b^{\prime}
$$

Using (A5) and (A6), we then get:

$$
c^{\prime}>(1-\delta) a+\delta b^{\prime}>b^{\prime},
$$

which contradicts (A1). Thus, $c^{\prime}<c$ must hold, establishing the Lemma.

In case (ii), there are two possibilities: (a) $b=b^{\prime}$; (b) $b<b^{\prime}$. In case (a), suppose, contrary to (A2), that $c^{\prime}:=f\left(a^{\prime}, b^{\prime}\right)>f(a, b)=: c$. Then, using (A1), we have:

$$
c<c^{\prime} \leq b^{\prime}=b
$$

Since $c<b$, we can infer from (f) that:

$$
c=(1-\delta) a+\delta b
$$

and that $a<b$. Then, using (A7) and (A8), we have:

$$
c^{\prime}>c=(1-\delta) a+\delta b>(1-\delta) a^{\prime}+\delta b^{\prime}
$$

Thus, by (f), we must have:

$$
c^{\prime}=b^{\prime} \text { and } a^{\prime}>b^{\prime}
$$

Using (A9) and (A10), we then get:

$$
c^{\prime}>(1-\delta) a^{\prime}+\delta b^{\prime}>b^{\prime}
$$

which contradicts (A1). Thus, $c^{\prime} \leq c$ must hold, establishing (A2) in this case.

In case (ii)(b), it follows from cases (ii)(a) and (i) that $f(a, b) \leq f\left(a^{\prime}, b\right)<f\left(a^{\prime}, b^{\prime}\right)$, establishing both statements of the Lemma. 
Let ${ }_{0} \mathbf{x} \in \mathbf{X}_{\delta}$ be given. For each $T \in \mathbb{N}$, define the finite sequence $\{z(0, T), \ldots, z(T-$ $1, T), z(T, T)\}$ by (1). Notice that this sequence is well-defined since $(1-\delta) \sum_{\tau=T}^{\infty} \delta^{\tau-T} U\left(x_{\tau}\right)$ $\in Z$, keeping in mind that $U$ satisfies (U.1). At each stage of the backward iteration (that is for $t=T-1, T-2, \ldots, 0$ ) we have $z(t, T) \in Z$ by (f), since $U\left(x_{t}\right) \in Z$ for all $t \in \mathbb{Z}_{+}$.

Using Lemma 7 , we can now compare $z(0, T)$ with $z(0, T+1)$, for each $T \in \mathbb{N}$.

Lemma 8 For each $T \in \mathbb{N}$, we have:

$$
z(t, T) \geq z(t, T+1) \text { for all } t \in\{0, \ldots, T-1\} .
$$

Proof. Given $T \in \mathbb{N}$, we have, from (A1) and (1),

$$
\begin{aligned}
z(T, T+1) & \leq(1-\delta) U\left(x_{T}\right)+\delta\left[(1-\delta) \sum_{\tau=T+1}^{\infty} \delta^{\tau-T} U\left(x_{\tau}\right)\right] \\
& =(1-\delta) \sum_{\tau=T}^{\infty} \delta^{\tau-T} U\left(x_{\tau}\right)=z(T, T) .
\end{aligned}
$$

Thus, applying Lemma 7, we have:

$$
z(T-1, T+1)=f\left(U\left(x_{T-1}\right), z(T, T+1)\right) \leq f\left(U\left(x_{T-1}\right), z(T, T)\right)=z(T-1, T) .
$$

Using Lemma 7 repeatedly, we then obtain:

$$
z(t, T+1) \leq z(t, T) \text { for all } t \in\{0, \ldots, T-1\}
$$

which establishes (A11).

With these results, we can show that $\bar{W}: \mathbf{X}_{\delta} \rightarrow \mathbb{R}$ defined by $(\overline{\mathrm{W}})$ is a well-defined SDU SWF, thereby establishing existence.

Proposition 5 The mapping $\bar{W}: \mathbf{X}_{\delta} \rightarrow \mathbb{R}$ defined by $(\overline{\mathrm{W}})$ is well-defined and satisfies (W.1)-(W.4).

Proof. By Lemma 8, we have $\{z(0, T)\}$ monotonically non-increasing in $T \in \mathbb{N}$, and it is bounded below by $U(0)$, so it converges. Thus, $\bar{W}$ is well-defined by $(\overline{\mathrm{W}})$, and $\bar{W}$ maps $\mathbf{X}_{\delta}$ to $Z$ since $z(0, T) \leq z(0,1)$ for all $T \in \mathbb{N}$ and $z(0,1) \in Z$.

By Lemma 8 , we have $\{z(t, T)\}$ monotonically non-increasing in $T>t$, and it is bounded below by $U(0)$, so it also converges. An implication of $(\overline{\mathrm{W}})$ is that

$$
\bar{W}\left({ }_{t} \mathbf{x}\right)=\lim _{T \rightarrow \infty} z(t, T)
$$

for all $t \in \mathbb{N}$. 
To establish (W.1), let ${ }_{0} \mathbf{x} \in \mathbf{X}_{\delta}$. We split up the analysis into three cases: (i) $U\left(x_{0}\right)>$ $\bar{W}\left({ }_{1} \mathbf{x}\right)$; (ii) $U\left(x_{0}\right)<\bar{W}\left({ }_{1} \mathbf{x}\right)$; (iii) $U\left(x_{0}\right)=\bar{W}\left({ }_{1} \mathbf{x}\right)$.

In case (i), using (A12), there is some $N \in \mathbb{N}$, such that for all $T \geq N$,

$$
U\left(x_{0}\right)>z(1, T)
$$

Thus, by (f) and (1), we have $z(0, T)=z(1, T)$ for all $T \geq N$. Using $(\overline{\mathrm{W}})$ and (A12), we obtain $\bar{W}\left({ }_{0} \mathbf{x}\right)=\bar{W}\left({ }_{1} \mathbf{x}\right)$, as required in (W.1).

In case (ii), using (A12), there is some $N \in \mathbb{N}$, such that for all $T \geq N$,

$$
U\left(x_{0}\right)<z(1, T)
$$

Thus, by (f) and (1), we have $z(0, T)=(1-\delta) U\left(x_{0}\right)+\delta z(1, T)$ for all $T \geq N$. Using $(\overline{\mathrm{W}})$ and $(\mathrm{A} 12)$, we obtain $\bar{W}\left({ }_{0} \mathbf{x}\right)=(1-\delta) U\left(x_{0}\right)+\delta \bar{W}\left({ }_{1} \mathbf{x}\right)$, as required in (W.1).

In case (iii), there are two possibilities: (a) there is a subsequence of $T$ for which $z(1, T)=$ $U\left(x_{0}\right)$; (b) there is $N \in \mathbb{N}$, such that for all $T \geq N$, we have $z(1, T) \neq U\left(x_{0}\right)$. In case (a), using (f) and (1), we have $z(0, T)=z(1, T)$ for the subsequence of $T$ (for which $z(1, T)=$ $\left.U\left(x_{0}\right)\right)$. Thus, using $(\overline{\mathrm{W}})$ and $(\mathrm{A} 12)$, we have $\bar{W}\left({ }_{0} \mathbf{x}\right)=\bar{W}\left({ }_{1} \mathbf{x}\right)$. But, since $U\left(x_{0}\right)=\bar{W}\left({ }_{1} \mathbf{x}\right)$ in case (iii), this yields $\bar{W}\left({ }_{0} \mathbf{x}\right)=(1-\delta) U\left(x_{0}\right)+\delta \bar{W}\left({ }_{1} \mathbf{x}\right)$, as required in (W.1).

In case (iii)(b), either (A) there is a subsequence of $T$ for which $U\left(x_{0}\right)<z(1, T)$, or (B) there is a subsequence of $T$ for which $U\left(x_{0}\right)>z(1, T)$, or both. In case (A), following the proof of case (ii), we get $\bar{W}\left({ }_{0} \mathbf{x}\right)=(1-\delta) U\left(x_{0}\right) \bar{W}\left({ }_{1} \mathbf{x}\right)$, as required in (W.1). In case (B), following the proof of case (i), we get $\bar{W}\left({ }_{0} \mathbf{x}\right)=\bar{W}\left({ }_{1} \mathbf{x}\right)$. But, since $U\left(x_{0}\right)=\bar{W}\left({ }_{1} \mathbf{u}\right)$ in case (iii), this yields $\bar{W}\left({ }_{0} \mathbf{x}\right)=(1-\delta) U\left(x_{0}\right)+\delta \bar{W}\left({ }_{1} \mathbf{x}\right)$, as required in (W.1).

To establish (W.2), let ${ }_{0} \mathbf{x}$ be an egalitarian stream. By (f) and (1), for each $T \in \mathbb{N}$, we have $z(t, T)=U\left(x_{0}\right)$ for $t \in\{0, \ldots, T-1\}$. Thus, $(\overline{\mathrm{W}})$ implies that $\bar{W}\left({ }_{0} \mathbf{x}\right)=U\left(x_{0}\right)$.

To establish (W.3), consider ${ }_{0} \mathbf{x}^{\prime},{ }_{0} \mathbf{x}^{\prime \prime} \in \mathbf{X}_{\delta}$ with ${ }_{0} \mathbf{x}^{\prime} \geq{ }_{0} \mathbf{x}^{\prime \prime}$. We want to show that $\bar{W}\left({ }_{0} \mathbf{x}^{\prime}\right) \geq \bar{W}\left({ }_{0} \mathbf{x}^{\prime \prime}\right)$, as required in (W.3). Define in obvious notation, for each $T \in \mathbb{N}$, the finite sequences $\left\{z^{\prime}(0, T), \ldots, z^{\prime}(T-1, T), z^{\prime}(T, T)\right\}$ and $\left\{z^{\prime \prime}(0, T), \ldots, z^{\prime \prime}(T-1, T), z^{\prime \prime}(T, T)\right\}$ as in (1). By Lemma 7 and (1), for each $T \in \mathbb{N}$, we have $z^{\prime}(t, T) \geq z^{\prime \prime}(t, T)$ for $t \in$ $\{0, \ldots, T-1\}$. Then, by $(\overline{\mathrm{W}}), \bar{W}\left({ }_{0} \mathbf{x}^{\prime}\right) \geq \bar{W}\left({ }_{0} \mathbf{x}^{\prime \prime}\right)$.

To establish (W.4), let ${ }_{0} \mathbf{x} \in \mathbf{X}_{\delta}$. We want to show that $\lim _{T \rightarrow \infty} \delta^{t} \bar{W}\left({ }_{T} \mathbf{x}\right)=0$, as required in (W.4). By Lemma 7 and (1), for each $T^{\prime} \in \mathbb{N}$, we have

$$
z\left(T, T^{\prime}\right) \leq(1-\delta) \sum_{t=T}^{\infty} \delta^{t-T} U\left(x_{t}\right)
$$


for $T \in\left\{0, \ldots, T^{\prime}-1\right\}$. Hence, by (A12),

$$
\bar{W}\left({ }_{T} \mathbf{u}\right)=\lim _{T^{\prime} \rightarrow \infty} z\left(T, T^{\prime}\right) \leq(1-\delta) \sum_{t=T}^{\infty} \delta^{t-T} U\left(x_{t}\right)
$$

for $T \in \mathbb{Z}_{+}$. Since $Z$ is bounded below, there does not exist $\varepsilon>0$ and a subsequence $T$ for which $\delta^{T} \bar{W}\left({ }_{T} \mathbf{x}\right) \leq-\varepsilon$. Suppose there exists $\varepsilon>0$ and a subsequence $T$ for which $\delta^{T} \bar{W}\left({ }_{T} \mathbf{x}\right) \geq \varepsilon$. By (A13), for all $T$ in the subsequence,

$$
0<\varepsilon \leq \delta^{T} \bar{W}\left({ }_{T} \mathbf{x}\right) \leq \delta^{T}(1-\delta) \sum_{t=T}^{\infty} \delta^{t-T} U\left(x_{t}\right)=(1-\delta) \sum_{t=T}^{\infty} \delta^{t} U\left(x_{t}\right) .
$$

This contradicts that $\lim _{T \rightarrow \infty}(1-\delta) \sum_{t=T}^{\infty} \delta^{t} U\left(x_{t}\right)=0$ for all ${ }_{0} \mathbf{x} \in \mathbf{X}_{\delta}$. Hence, it follows that $\lim _{T \rightarrow \infty} \delta^{t} \bar{W}\left({ }_{0} \mathbf{x}^{\prime}\right)=0$.

\section{A.2 Verifying the Axioms}

We now verify that any SDU SWF satisfies the axioms $\mathbf{O}, \mathbf{M}, \mathbf{I F}, \mathbf{R D}, \mathbf{H E F}$ and RC: Order, Monotonicity, Independent Future, Restricted Dominance, Hammond Equity for the Future, and Restricted Continuity. The axioms are explained below in the course of verifying them (observe that axiom IF implies Koopmans' (1960) stationary condition). This entails that any SDU SWF is a sustainable recursive SWF, as defined by Asheim, Mitra and Tungodden (2008).

To this end, fix $\delta \in(0,1)$ and $U: \mathbb{R}_{+} \rightarrow \mathbb{R}$ satisfying (U.1), assume that the function $W: \mathbf{X}_{\delta} \rightarrow \mathbb{R}$ satisfies (W.1)-(W.4) (note, however, that condition (W.4) is not needed to verify the axioms), and define a social welfare relation (SWR) $\succsim$ by:

$$
\text { For }{ }_{0} \mathbf{x}^{\prime},{ }_{0} \mathbf{x}^{\prime \prime} \in \mathbf{X}_{\delta},{ }_{0} \mathbf{x}^{\prime} \succsim{ }_{0} \mathbf{x}^{\prime \prime} \text { if and only if } W\left({ }_{0} \mathbf{x}^{\prime}\right) \geq W\left({ }_{0} \mathbf{x}^{\prime \prime}\right) \text {. }
$$

By definition, then, $\succsim$ must be a complete order, so axiom $\mathbf{O}$ is satisfied. Further, axiom $\mathbf{M}$ is equivalent to (W.3).

\section{Axiom IF}

Let ${ }_{0} \mathbf{x}^{\prime},{ }_{0} \mathbf{x}^{\prime \prime} \in \mathbf{X}_{\delta}$ with $x_{0}^{\prime}=x_{0}^{\prime \prime}=x_{0}$. We want to show that ${ }_{0} \mathbf{x}^{\prime} \succsim{ }_{0} \mathbf{x}^{\prime \prime}$ holds if and only if ${ }_{1} \mathbf{x}^{\prime} \succsim{ }_{1} \mathbf{x}^{\prime \prime}$ to verify axiom $\mathbf{I F}$.

Assume first that ${ }_{1} \mathbf{x}^{\prime} \succsim{ }_{1} \mathbf{x}^{\prime \prime}$. Then, $W\left({ }_{0} \mathbf{x}^{\prime}\right) \geq W\left({ }_{0} \mathbf{x}^{\prime \prime}\right)$, and, by (W.1),

$$
\begin{aligned}
& W\left({ }_{0} \mathbf{x}^{\prime}\right)=f\left(U\left(x_{0}\right), W\left({ }_{0} \mathbf{x}^{\prime}\right)\right) \\
& W\left({ }_{0} \mathbf{x}^{\prime \prime}\right)=f\left(U\left(x_{0}\right), W\left({ }_{0} \mathbf{x}^{\prime \prime}\right)\right)
\end{aligned}
$$


Thus, applying Lemma 7 , we have $W\left({ }_{1} \mathbf{x}^{\prime}\right) \geq W\left({ }_{1} \mathbf{x}^{\prime \prime}\right)$ and ${ }_{0} \mathbf{x}^{\prime} \succsim{ }_{0} \mathbf{x}^{\prime \prime}$.

Assume next that ${ }_{1} \mathbf{x}^{\prime} \succ{ }_{1} \mathbf{x}^{\prime \prime}$. Then, $W\left({ }_{0} \mathbf{x}^{\prime}\right)>W\left({ }_{0} \mathbf{x}^{\prime \prime}\right)$, and (A14) and (A15) hold. Thus, by Lemma 7 , we have $W\left({ }_{1} \mathbf{x}^{\prime}\right)>W\left({ }_{1} \mathbf{x}^{\prime \prime}\right)$ and ${ }_{0} \mathbf{x}^{\prime} \succ{ }_{0} \mathbf{x}^{\prime \prime}$.

This completes the verification of Axiom IF since $\succsim$ is complete.

\section{Axiom RD}

Let ${ }_{0} \mathbf{x}^{\prime},{ }_{0} \mathbf{x}^{\prime \prime} \in \mathbf{X}_{\delta}$ satisfy $x_{0}^{\prime}=x>x_{0}^{\prime \prime}$ and $x_{0}^{\prime}=x=x_{0}^{\prime \prime}$ for all $t \geq 1$. We want to show that ${ }_{0} \mathbf{x}^{\prime} \succ{ }_{0} \mathbf{x}^{\prime \prime}$ to verify axiom RD. By (W.2),

$$
W\left({ }_{1} \mathbf{x}^{\prime}\right)=U(x)=W\left({ }_{1} \mathbf{x}^{\prime \prime}\right) .
$$

Since $x_{0}^{\prime}=x>x_{0}^{\prime \prime}$, it follows from (A16) that $U\left(x_{0}^{\prime}\right)=W\left({ }_{1} \mathbf{x}^{\prime}\right)$ and $U\left(x_{0}^{\prime \prime}\right)<W\left({ }_{1} \mathbf{x}^{\prime \prime}\right)$. Hence, by (W.1),

$$
W\left({ }_{0} \mathbf{x}^{\prime}\right)=(1-\delta) U\left(x_{0}^{\prime}\right)+W\left({ }_{0} \mathbf{x}^{\prime}\right)>(1-\delta) U\left(x_{0}^{\prime \prime}\right)+W\left({ }_{0} \mathbf{x}^{\prime \prime}\right)=W\left({ }_{0} \mathbf{x}^{\prime \prime}\right) .
$$

\section{Axiom HEF}

Let ${ }_{0} \mathbf{x}^{\prime},{ }_{0} \mathbf{x}^{\prime \prime} \in \mathbf{X}_{\delta}$ satisfy $x_{t}^{\prime}=x^{\prime}$ and $x_{t}^{\prime \prime}=x^{\prime \prime}$ for all $t \geq 1$, with

$$
x_{0}^{\prime \prime}>x_{0}^{\prime}>x^{\prime}>x^{\prime \prime} .
$$

We want to show that ${ }_{0} \mathbf{x}^{\prime} \succ{ }_{0} \mathbf{x}^{\prime \prime}$ to verify axiom HEF. Using the fact that $x_{0}^{\prime}>x^{\prime}$, we have $U\left(x_{0}^{\prime}\right)>U\left(x^{\prime}\right)=W\left({ }_{1} \mathbf{x}^{\prime}\right)$, using (W.2). Thus, by (W.1), we must have $W\left({ }_{0} \mathbf{x}^{\prime}\right)=W\left({ }_{1} \mathbf{x}^{\prime}\right)$. Similarly, using the fact that $x_{0}^{\prime}>x^{\prime}$, we have $U\left(x_{0}^{\prime \prime}\right)>U\left(x^{\prime \prime}\right)=W\left({ }_{1} \mathbf{x}^{\prime \prime}\right)$, using (W.2). Thus, by (W.1), we must have $W\left({ }_{0} \mathbf{x}^{\prime \prime}\right)=W\left({ }_{1} \mathbf{x}^{\prime \prime}\right)$. By (A17), $x^{\prime}>x^{\prime \prime}$, implying that $W\left({ }_{1} \mathbf{x}^{\prime}\right)=U\left(x^{\prime}\right)>U\left(x^{\prime \prime}\right)=W\left({ }_{1} \mathbf{x}^{\prime \prime}\right)$. Thus, $W\left({ }_{0} \mathbf{x}^{\prime}\right)>W\left({ }_{0} \mathbf{x}^{\prime \prime}\right)$ holds, and so ${ }_{0} \mathbf{x}^{\prime} \succ{ }_{0} \mathbf{x}^{\prime \prime}$.

\section{Axiom RC}

Let ${ }_{0} \mathbf{x}^{\prime}{ }_{0} \mathbf{x}^{\prime \prime} \in \mathbf{X}_{\delta}$ with $x_{t}^{\prime}=x$ for all $t \geq 1$. Let ${ }_{0} \mathbf{x}^{n} \in \mathbf{X}_{\delta}$ for $n \in \mathbb{N}$ with the property that ${ }_{0} \mathbf{x}^{n} \succsim{ }_{0} \mathbf{x}^{\prime \prime}$ for all $n \in \mathbb{N}$ and

$$
\lim _{n \rightarrow \infty} \sup _{t \geq 0}\left|x_{t}^{n}-x_{t}^{\prime}\right|=0 .
$$

We have to show that ${ }_{0} \mathbf{x}^{\prime} \succsim{ }_{0} \mathbf{x}^{\prime \prime}$ to verify axiom $\mathbf{R C}$.

We first claim that $W\left({ }_{0} \mathbf{x}^{\prime \prime}\right) \leq U(x)$. Suppose, on the contrary, that $W\left({ }_{0} \mathbf{x}^{\prime \prime}\right)>U(x)$. Then, denoting $W\left({ }_{0} \mathbf{x}^{\prime \prime}\right)$ by $\xi$, we note that $\xi \in(U(x), \infty)$. 
Choose $\varepsilon^{\prime}>0$ such that $U\left(x+\varepsilon^{\prime}\right)<\xi$. Using (A18), we can choose $N \in \mathbb{N}$ such that $x_{t}^{N} \leq x_{t}^{\prime}+\varepsilon^{\prime}=x+\varepsilon^{\prime}$ for all $t \geq 1$. Then, by (W.1)-(W.3) and (A1),

$$
W\left({ }_{0} \mathbf{x}^{\prime \prime}\right) \leq W\left({ }_{0} \mathbf{x}^{N}\right) \leq W\left({ }_{1} \mathbf{x}^{N}\right) \leq U\left(x_{t}^{\prime}+\varepsilon^{\prime}\right)<\xi=W\left({ }_{0} \mathbf{x}^{\prime \prime}\right)
$$

a contradiction. This establishes our claim that $W\left({ }_{0} \mathbf{x}^{\prime \prime}\right) \leq U(x)$ Thus, we have $W\left({ }_{0} \mathbf{x}^{\prime \prime}\right) \leq$ $W\left({ }_{1} \mathbf{x}^{\prime}\right)$ by (W.2).

Next, we claim that $W\left({ }_{0} \mathbf{x}^{\prime \prime}\right) \leq W\left({ }_{0} \mathbf{x}^{\prime}\right)$. Suppose, on the contrary that $\eta:=\left[W\left({ }_{0} \mathbf{x}^{\prime \prime}\right)-\right.$ $\left.W\left({ }_{0} \mathbf{x}^{\prime}\right)\right]>0$. Then, by (W.2) and (W.3), we have

$$
U(0) \leq W\left({ }_{0} \mathbf{x}^{\prime}\right)<W\left({ }_{0} \mathbf{x}^{\prime \prime}\right) \leq U(x)
$$

so that $U(x)-U(0) \geq \eta>0$. Using (A18), we can choose $N \in \mathbb{N}$ so that $\bar{x}^{N}:=\sup _{t \geq 1} x_{t}^{N}$ and $\underline{x}^{N}:=\inf _{t \geq 1} x_{t}^{N}$ exist and

$$
\left|U\left(x_{0}^{N}\right)-U\left(x_{0}^{\prime}\right)\right|<\eta, \quad U\left(\bar{x}^{N}\right)<U(x)+\eta, \quad U\left(\underline{x}^{N}\right)>U(x)-\eta .
$$

Note that it follows from (A1) that, whenever $(a, b) \in Z^{2}$ and $\left(a^{\prime}, b^{\prime}\right) \in Z^{2}$ satisfy $\left|a^{\prime}-a\right|<\eta$ and $\left|b^{\prime}-b\right|<\eta$, we must have

$$
\left|f\left(a^{\prime}, b^{\prime}\right)-f(a, b)\right|<\eta \text {. }
$$

We now show that:

$$
\left|W\left({ }_{0} \mathbf{x}^{N}\right)-W\left({ }_{0} \mathbf{x}^{\prime}\right)\right|<\eta .
$$

Note that by (A19), $W\left({ }_{1} \mathbf{x}^{N}\right) \leq U\left(\bar{x}^{N}\right)<U(x)+\eta=W\left({ }_{1} \mathbf{x}^{\prime}\right)+\eta$, using (W.2) and (W.3). Similarly, $W\left({ }_{1} \mathbf{x}^{N}\right) \geq U\left(\underline{x}^{N}\right)>U(x)-\eta=W\left({ }_{1} \mathbf{x}^{\prime}\right)-\eta$. Thus,

$$
\left|W\left({ }_{1} \mathbf{x}^{N}\right)-W\left({ }_{1} \mathbf{x}^{\prime}\right)\right|<\eta
$$

We have $W\left({ }_{0} \mathbf{x}^{N}\right)=f\left(x_{0}^{N}, W\left({ }_{1} \mathbf{x}^{N}\right)\right)$ and $W\left({ }_{0} \mathbf{x}^{\prime}\right)=f\left(x_{0}^{\prime}, W\left({ }_{1} \mathbf{x}^{\prime}\right)\right)$. Thus, using (A19), (A20) and (A22), we obtain (A21).

In particular, (A21) implies that:

$$
W\left({ }_{0} \mathbf{x}^{\prime}\right)+\eta=W\left({ }_{0} \mathbf{x}^{\prime \prime}\right) \leq W\left({ }_{0} \mathbf{x}^{N}\right)<W\left({ }_{0} \mathbf{x}^{\prime}\right)+\eta
$$

a contradiction. This establishes the claim that $W\left({ }_{0} \mathbf{x}^{\prime}\right) \geq W\left({ }_{0} \mathbf{x}^{\prime \prime}\right)$ and so ${ }_{0} \mathbf{x}^{\prime} \succsim{ }_{0} \mathbf{x}^{\prime \prime}$.

The same kind of argument can be used to show ${ }_{0} \mathrm{x}^{\prime} \precsim{ }_{0} \mathrm{x}^{\prime \prime}$ if ${ }_{0} \mathrm{x}^{n} \precsim{ }_{0} \mathbf{x}^{\prime \prime}$ for all $n \in \mathbb{N}$. 


\section{A.3 Properties of Sustainable Discounted Utilitarian SWFs}

We now study (given $\delta \in(0,1)$ and $U: \mathbb{R}_{+} \rightarrow \mathbb{R}$ satisfying (U.1)) the properties of any function $W: \mathbf{X}_{\delta} \rightarrow \mathbb{R}$ satisfying (W.1)-(W.4).

We first state a result concerning the limit behavior of $W\left({ }_{t} \mathbf{x}\right)$ as $t \rightarrow \infty$ if the consumption stream ${ }_{0} \mathbf{x}$ is bounded.

Proposition 6 If $W$ is an $S D U S W F$, then, for every ${ }_{0} \mathbf{x} \in \mathbf{X}_{\varphi}$,

$$
\begin{aligned}
& \text { (i) } \lim _{t \rightarrow \infty} W\left({ }_{t} \mathbf{x}\right) \text { exists } \\
& \text { (ii) } \lim _{t \rightarrow \infty} W\left({ }_{t} \mathbf{x}\right)=\liminf _{t \rightarrow \infty} U\left(x_{t}\right) \text {. }
\end{aligned}
$$

Proof. Since, as established in Section A.2, any SDU SWF satisfies the axioms O, M, IF, RD, HEF and RC, this result follows from Asheim, Mitra and Tungodden (2008, Proposition 7).

As reported by the following proposition, this result can be used to establish that there is the unique SDU SWF on the set of bounded consumption streams.

Proposition 7 Any SDU SWF W restricted to $\mathbf{X}_{\varphi}$ coincides with $\bar{W}$ restricted to $\mathbf{X}_{\varphi}$.

Proof. Suppose there are two SDU SWFs, call them $W$ and $V$, such that $W\left({ }_{0} \mathbf{x}\right) \neq$ $V\left({ }_{0} \mathbf{x}\right)$ for some ${ }_{0} \mathbf{x} \in \mathbf{X}_{\varphi}$. Without loss of generality, let $W\left({ }_{0} \mathbf{x}\right)>V\left({ }_{0} \mathbf{x}\right)$. If $W\left({ }_{1} \mathbf{x}\right) \leq V\left({ }_{1} \mathbf{x}\right)$, then by Lemma 7:

$$
V\left({ }_{0} \mathbf{x}\right)=f\left(U\left(x_{0}\right), V\left({ }_{1} \mathbf{x}\right)\right) \geq f\left(U\left(x_{0}\right), W\left({ }_{1} \mathbf{x}\right)\right)=W\left({ }_{0} \mathbf{x}\right)
$$

where $f$ is defined by (f). This is a contradiction. Thus, we must have $W\left({ }_{1} \mathbf{x}\right)>V\left({ }_{1} \mathbf{x}\right)$, and by repeating this step we obtain:

$$
W\left({ }_{t} \mathbf{x}\right)>V\left({ }_{t} \mathbf{x}\right) \text { for all } t \geq 0 .
$$

We also know from Proposition 6 that:

$$
\lim _{t \rightarrow \infty} W\left({ }_{t} \mathbf{x}\right)=\lim _{t \rightarrow \infty} V\left({ }_{t} \mathbf{x}\right)=\liminf _{t \rightarrow \infty} U\left(x_{t}\right) .
$$

Thus, defining a sequence $\left\{k_{t}\right\}$ by $k_{t}=\left[W\left({ }_{t} \mathbf{x}\right)-V\left({ }_{t} \mathbf{x}\right)\right]$ for all $t \geq 0$, we see from (A23) and (A24) that $k_{t}>0$ for all $t \geq 0$, and $k_{t} \rightarrow 0$ as $t \rightarrow \infty$. It follows that there is some $n$ for which we must have $k_{n+1}<k_{n}$. That is, we have:

$$
0<\left[W\left({ }_{n+1} \mathbf{x}\right)-V\left({ }_{n+1} \mathbf{x}\right)\right]<\left[W\left({ }_{n} \mathbf{x}\right)-V\left({ }_{n} \mathbf{x}\right)\right]
$$


We then consider three possibilities: (i) $U\left(x_{n}\right) \geq W\left({ }_{n+1} \mathbf{x}\right)$, (ii) $U\left(x_{n}\right) \leq V\left({ }_{n+1} \mathbf{x}\right)$, and (iii) $V\left({ }_{n+1} \mathbf{x}\right)<U\left(x_{n}\right)<W\left({ }_{n+1} \mathbf{x}\right)$. If (i) holds, then $U\left(x_{n}\right)>W\left({ }_{n+1} \mathbf{x}\right)$, and so we have by (W.1):

$$
\left.\begin{array}{l}
\text { (i) } W\left({ }_{n} \mathbf{x}\right)=W\left({ }_{n+1} \mathbf{x}\right) \\
\text { (ii) } V\left({ }_{n} \mathbf{x}\right)=V\left({ }_{n+1} \mathbf{x}\right)
\end{array}\right\}
$$

But (A26) clearly contradicts (A25).

If (ii) holds, then $U\left(x_{n}\right)<W\left({ }_{n+1} \mathbf{x}\right)$, and so we have by (W.1):

$$
\left.\begin{array}{l}
\text { (i) } W\left({ }_{n} \mathbf{x}\right)=(1-\delta) U\left(x_{n}\right)+W\left({ }_{n+1} \mathbf{x}\right) \\
\text { (ii) } V\left({ }_{n} \mathbf{x}\right)=(1-\delta) U\left(x_{n}\right)+V\left({ }_{n+1} \mathbf{x}\right)
\end{array}\right\}
$$

But (A27) implies that $\left.\left[W{ }_{n} \mathbf{x}\right)-V\left({ }_{n} \mathbf{x}\right)\right]=\delta\left[W\left(_{n+1} \mathbf{x}\right)-V\left({ }_{n+1} \mathbf{x}\right)\right]$, which again contradicts (A25).

If (iii) holds, then we have by (W.1):

$$
\left.\begin{array}{c}
\text { (i) } W\left({ }_{n} \mathbf{x}\right)=(1-\delta) U\left(x_{n}\right)+W\left({ }_{n+1} \mathbf{x}\right) \\
\text { (ii) } V\left({ }_{n} \mathbf{x}\right)=V\left({ }_{n+1} \mathbf{x}\right)
\end{array}\right\}
$$

By (A28)(i) and $U\left(x_{n}\right)<W\left({ }_{n+1} \mathbf{x}\right)$, we get $W\left({ }_{n} \mathbf{x}\right)<(1-\delta) W\left({ }_{n+1} \mathbf{x}\right)+\delta W\left({ }_{n+1} \mathbf{x}\right)=$ $W\left({ }_{n+1} \mathbf{x}\right)$, and so by $(\mathrm{A} 28)(\mathrm{ii})$, we get $\left[W\left({ }_{n} \mathbf{x}\right)-V\left({ }_{n} \mathbf{x}\right)\right]=\left[W\left({ }_{n} \mathbf{x}\right)-V\left({ }_{n+1} \mathbf{x}\right)\right]<\left[W\left({ }_{n+1} \mathbf{x}\right)-\right.$ $\left.V\left({ }_{n+1} \mathbf{x}\right)\right]$, which again contradicts (A25).

Since these are the only possibilities, there do not exist two SDU SWFs, $W$ and $V$, such that $W\left({ }_{0} \mathbf{x}\right) \neq V\left({ }_{0} \mathbf{x}\right)$ for some ${ }_{0} \mathbf{x} \in \mathbf{X}_{\varphi}$. The result follows since, by Proposition $5, \bar{W}$ is an SDU SWF.

\section{A.4 Non-Uniqueness of Sustainable Discounted Utilitarian SWF}

This uniqueness result does not carry over to unbounded consumption streams. To show this, we provide another function $W: \mathbf{X}_{\delta} \rightarrow \mathbb{R}$ satisfying (W.1)-(W.4). Let ${ }_{0} \mathbf{x} \in \mathbf{X}_{\varphi}$ be given. For each $T \in \mathbb{N}$, define the finite sequence $\{\tilde{w}(0, T), \ldots, \tilde{w}(T-1, T), \tilde{w}(T, T)\}$ as follows:

$$
\begin{aligned}
& \tilde{w}(T, T)=\liminf _{t \rightarrow \infty} U\left(x_{t}\right) \\
& \tilde{w}(T-1, T)=f\left(U\left(x_{T-1}\right), \tilde{w}(T, T)\right) \\
& \ldots \\
& \tilde{w}(0, T)=f\left(U\left(x_{0}\right), \tilde{w}(1, T)\right)
\end{aligned}
$$

We now define $\tilde{W}\left({ }_{0} \mathbf{x}\right)$ on $\mathbf{X}_{\varphi}$ by

$$
\tilde{W}\left({ }_{0} \mathbf{x}\right):=\lim _{T \rightarrow \infty} \tilde{w}(0, T) .
$$


Extend the domain of $\tilde{W}$ to $\mathbf{X}_{\delta}$ as follows. If ${ }_{0} \mathbf{x} \in \mathbf{X}_{\delta} \backslash \mathbf{X}_{\varphi}$ has the property that $\liminf _{t \rightarrow \infty}$ $U\left(x_{t}\right)$ exists, then the algorithm ( $\left.\tilde{W}\right)$ is still applicable. If ${ }_{0} \mathbf{x} \in \mathbf{X}_{\delta} \backslash \mathbf{X}_{\varphi}$ does not have this property, construct each stream in the sequence $\left\{{ }_{0} \mathbf{x}^{n}\right\}_{n \in \mathbb{N}}$ as follows:

$$
x_{t}^{n}= \begin{cases}n & \text { if } \quad \forall \tau \geq t, x_{\tau} \geq n \\ x_{t} & \text { if } \quad \exists \tau \geq t \text { s.t. } x_{\tau}<n,\end{cases}
$$

and, since ${ }_{0} \mathbf{x}^{n} \in \mathbf{X}_{\varphi}$ for each $n \in \mathbb{N}$, define $\tilde{W}\left({ }_{0} \mathbf{x}\right)$ in the following way:

$$
\tilde{W}\left({ }_{0} \mathbf{x}\right):=\lim _{n \rightarrow \infty} \tilde{W}\left({ }_{0} \mathbf{x}^{n}\right) .
$$

It can be shown that $\tilde{W}: \mathbf{X}_{\delta} \rightarrow \mathbb{R}$ satisfies (W.1)-(W.4) and is thus an SDU SWF.

Example of non-uniqueness. Let $\delta=\frac{1}{2}$ and $U(x)=x^{a}$, where $\frac{1}{2}<a<1$, implying that $U: \mathbb{R}_{+} \rightarrow \mathbb{R}$ satisfies (U.1) and (U.2). Consider

$$
{ }_{0} \mathbf{X}=\left(2^{\frac{0}{a}}, 0,2^{\frac{1}{a}}, 0,2^{\frac{2}{a}}, 0,2^{\frac{3}{a}}, 0, \ldots\right) \in \mathbf{X}_{\frac{1}{2}},
$$

leading to the utility stream ${ }_{0} \mathbf{u}=(1,0,2,0,4,0,8,0, \ldots)$. Then

$$
\tilde{W}\left({ }_{0} \mathbf{x}\right)=0<1=\bar{W}\left({ }_{0} \mathbf{x}\right) .
$$

It turns out, however, that $\bar{W}$ provides an upper bound for SDU welfare. This is stated in the following proposition.

Proposition 8 Any SDU SWFW satisfies $W\left({ }_{0} \mathbf{x}\right) \leq \bar{W}\left({ }_{0} \mathbf{x}\right)$ for all ${ }_{0} \mathbf{x} \in \mathbf{X}_{\delta}$.

To prove this result we need the following lemma.

Lemma 9 Assume that $W$ is an $S D U S W F$. If $0 \mathbf{x} \in \mathbf{X}_{\delta}$, then, for all $t \in \mathbb{Z}_{+}, W\left({ }_{t} \mathbf{x}\right) \leq$ $w\left({ }_{t} \mathbf{x}\right)$.

Proof. Suppose to the contrary that there is some $\tau \geq 0$ such that

$$
\varepsilon:=W\left({ }_{\tau} \mathbf{x}\right)-w\left({ }_{\tau} \mathbf{x}\right)>0 .
$$

It follows from (W.1) that, for all $t$,

$$
W\left({ }_{t} \mathbf{x}\right)=f\left(U\left(x_{t}\right), W\left({ }_{t+1} \mathbf{x}\right)\right) \leq(1-\delta) U\left(x_{t}\right)+\delta W\left({ }_{t+1} \mathbf{x}\right),
$$


where $f$ is defined by (f), while the definition of $w$ entails that, for all $t, w\left({ }_{t} \mathbf{x}\right)=(1-$ $\delta) U\left(x_{t}\right)+\delta w(t+1 \mathbf{x})$. Hence, (A29) implies that, for all $t>\tau$,

$$
W\left({ }_{t} \mathbf{x}\right)-w\left({ }_{t} \mathbf{x}\right) \geq \frac{\varepsilon}{\delta^{t-\tau}} .
$$

It now follows from (U.1) and the definition of $w$ that, for all $t>\tau$,

$$
\delta^{t} W\left({ }_{t} \mathbf{x}\right) \geq \delta^{t} w\left({ }_{t} \mathbf{x}\right)+\delta^{\tau} \varepsilon \geq \delta^{t} U(0)+\delta^{\tau} \varepsilon .
$$

This in turn implies the existence of $T \geq \tau$ such that, for all $t>T$,

$$
\delta^{t} W\left({ }_{t} \mathbf{x}\right) \geq \frac{1}{2} \delta^{\tau} \varepsilon>0
$$

thereby contradicting that $W$ satisfies (W.4).

Proof of Proposition 8. Let ${ }_{0} \mathbf{x} \in \mathbf{X}_{\delta}$. By Lemma 9 and (1), for all $T \in \mathbb{N}$, $W\left({ }_{T} \mathbf{x}\right) \leq w\left({ }_{T} \mathbf{x}\right)=z(T, T)$. Furthermore, by (W.1) and (1), for all $t \in\{0, \ldots, T-1\}$,

$$
\begin{aligned}
W\left({ }_{t} \mathbf{x}\right) & =f\left(U\left(x_{t}\right), W\left({ }_{t+1} \mathbf{x}\right)\right) \\
w(t, T) & =f\left(U\left(x_{t}\right), z(t+1, T)\right),
\end{aligned}
$$

where $f$ is defined by (f). By using Lemma 7 repeatedly, we obtain:

$$
W\left({ }_{0} \mathbf{x}\right) \leq z(0, T) .
$$

Since this holds for any $T \in \mathbb{N}$, the results follows from $(\overline{\mathrm{W}})$.

\section{A.5 Properties of Minimum Functions}

Since the properties of $f$ play a crucial role in determining the existence as well as the properties of SDU SWFs, it is of interest to study the nature of the function, $f$, defined by (f). This, in turn, leads to an analysis of properties of the "min" function. While these properties are elementary, they are not available in texts for ready reference. The purpose of this subsection is to provide a self-contained analysis of basic properties of "min" functions.

To this end, we study a function $g: Y \times Y \rightarrow Y$, defined by:

$$
g(a, b)=\min \{a, b\}
$$

We now prove that $g$ has the following properties.

(1) Monotonicity: If $(a, b) \in Z^{2}$ and $\left(a^{\prime}, b^{\prime}\right) \in Z^{2}$, and $\left(a^{\prime}, b^{\prime}\right) \geq(a, b)$, then $g\left(a^{\prime}, b^{\prime}\right) \geq$ $g(a, b)$. 
Proof. Without loss of generality, let $g(a, b)=a$. Then, $b \geq a$ and so $b^{\prime} \geq b \geq a$. If $g\left(a^{\prime}, b^{\prime}\right)=a^{\prime}$, then $g\left(a^{\prime}, b^{\prime}\right)=a^{\prime} \geq a=g(a, b)$. If $g\left(a^{\prime}, b^{\prime}\right)=b^{\prime}$, then $g\left(a^{\prime}, b^{\prime}\right)=b^{\prime} \geq b \geq a=$ $g(a, b)$.

(2) Uniformity: If $(a, b) \in Z^{2}$ and $\varepsilon>0$, then:

$$
\begin{array}{ll}
\text { (i) } g(a+\varepsilon, b+\varepsilon)=g(a, b)+\varepsilon & \text { if }(a+\varepsilon, b+\varepsilon) \in Z^{2}, \\
\text { (ii) } g(a-\varepsilon, b-\varepsilon)=g(a, b)-\varepsilon & \text { if }(a-\varepsilon, b-\varepsilon) \in Z^{2} .
\end{array}
$$

Proof. Without loss of generality let $g(a, b)=a$, so that $b \geq a$. If $(a+\varepsilon, b+\varepsilon) \in Z^{2}$, then since $b+\varepsilon \geq a+\varepsilon$, we have $g(a+\varepsilon, b+\varepsilon)=a+\varepsilon=g(a, b)+\varepsilon$. If $(a-\varepsilon, b-\varepsilon) \in Z^{2}$, then since $b-\varepsilon \geq a-\varepsilon$, we have $g(a-\varepsilon, b-\varepsilon)=a-\varepsilon=g(a, b)-\varepsilon$.

(3) Continuity: Let us define the open interval $(U(0), \infty)$ by $S$. If $(a, b) \in S^{2}$ and $\left(a^{\prime}, b^{\prime}\right) \in S^{2}$, and $\varepsilon>0$ satisfy

$$
\left|a^{\prime}-a\right|<\varepsilon \text {, and }\left|b^{\prime}-b\right|<\varepsilon,
$$

then:

$$
\left|g\left(a^{\prime}, b^{\prime}\right)-g(a, b)\right|<\varepsilon .
$$

Proof. Given (A30), we can choose $\varepsilon^{\prime} \in(0, \varepsilon)$, such that $0<a-\varepsilon^{\prime}<a+\varepsilon^{\prime}<1$, $0<b-\varepsilon^{\prime}<b+\varepsilon^{\prime}<1$, and

$$
\left|a^{\prime}-a\right| \leq \varepsilon^{\prime} \text {, and }\left|b^{\prime}-b\right| \leq \varepsilon^{\prime} .
$$

Then, we have $a^{\prime} \leq a+\varepsilon^{\prime}<1$ and $b^{\prime} \leq b+\varepsilon^{\prime}<1$, so that, using the monotonicity and uniformity properties of $g$, we obtain:

$$
g\left(a^{\prime}, b^{\prime}\right) \leq g\left(a+\varepsilon^{\prime}, b+\varepsilon^{\prime}\right)=g(a, b)+\varepsilon^{\prime}<g(a, b)+\varepsilon .
$$

Similarly, we have $a^{\prime} \geq a-\varepsilon^{\prime}>0$ and $b^{\prime} \geq b-\varepsilon^{\prime}>0$, so that, using the monotonicity and uniformity properties of $g$, we obtain:

$$
g\left(a^{\prime}, b^{\prime}\right) \geq g\left(a-\varepsilon^{\prime}, b-\varepsilon^{\prime}\right)=g(a, b)-\varepsilon^{\prime}>g(a, b)-\varepsilon .
$$

Clearly, (A32) and (A33) imply (A31).

Remark. The properties of $g$ can be applied to the function $f$, defined by (f) since

$$
f(a, b)=g((1-\delta) a+\delta b, b) \text { for all }(a, b) \in Z^{2} .
$$




\section{References}

Asheim, G.B. (1988), Rawlsian intergenerational justice as a Markov-perfect equilibrium in a resource technology. Review of Economic Studies 55, 469-483.

Asheim, G.B., Buchholz, W. and Tungodden, B. (2001), Justifying sustainability, Journal of Environmental Economics and Management 41, 252-268.

Asheim, G.B., Mitra, T. and Tungodden, B. (2007), A new equity condition for infinite utility streams and the possibility of being Paretian. In Roemer, J., Suzumura, K. (eds.), Intergenerational Equity and Sustainability. Palgrave-Macmillan, Basingstoke.

Asheim, G.B., Mitra, T. and Tungodden, B. (2008), Sustainable recursive social welfare functions. Memorandum 18/2006 (revised), Department of Economics, University of Oslo.

Asheim, G.B. and Tungodden, B. (2004), Do Koopmans postulates lead to discounted utilitarianism? Discussion Paper 32/04, Norwegian School of Economics and Business Administration.

Banerjee, K. (2006), On the equity-efficiency trade off in aggregating infinite utility streams. Economics Letters 93, 63-67.

Basu, K. and Mitra, T. (2003), Aggregating infinite utility streams with intergenerational equity: the impossibility of being Paretian. Econometrica 32, 1557-1563.

Basu, K. and Mitra, T. (2007), Possibility Theorems for Aggregating Infinite Utility Streams Equitably. In Roemer, J., Suzumura, K. (eds.), Intergenerational Equity and Sustainability. Palgrave-Macmillan, Basingstoke.

Beals, R. and Koopmans, T.C. (1969), Maximizing stationary utility in a constant technology. SIAM Journal of Applied Mathematics 17, 1001-1015.

Cass, D. and Mitra T. (1991), Indefinitely sustained consumption despite exhaustible natural resources. Economic Theory, 1, 119-46.

Cass, D. and Yaari, M.E. (1971). Present values playing the role of efficiency prices in the one-good growth model. Review of Economic Studies, 38, 331-339.

Dasgupta, P.S. and Heal, G.M. (1974), The optimal depletion of exhaustible resources. Review of Economic Studies (Symposium), 3-28. 
Dasgupta, P.S. and Heal, G.M. (1979), Economic Theory and Exhaustible Resources. Cambridge University Press, Cambridge, UK.

Dasgupta, S. and Mitra, T. (1983), Intergenerational equity and efficient allocation of exhaustible resources. International Economic Review 24, 133-53.

Epstein, L. (1986), Intergenerational consumption rules: An axiomatization of utilitarianism and egalitarianism. Journal of Economic Theory 38, 280-297.

Gaspart, F. and Gosseries, A. (2007), Are generational savings unjust? Politics, Philosophy E Economics 6, 193-217.

Koopmans, T.C. (1960), Stationary ordinal utility and impatience. Econometrica 28, 287309.

Pezzey, J. (1994), Theoretical Essays on Sustainability and Environmental Policy. Ph.D. Thesis, University of Bristol.

Pigou, A.C. (1932). The Economics of Welfare. Macmillan, London.

Ramsey, F. (1928). A mathematical theory of saving. Economic Journal, 38, 543-59.

Rawls, J. (1999), A Theory of Justice, revised edn. Oxford University Press, Oxford.

Solow, R.M. (1974), Intergenerational equity and exhaustible resources. Review of Economic Studies (Symposium), 29-45. 


\section{CESifo Working Paper Series}

for full list see www.cesifo-group.org/wp

(address: Poschingerstr. 5, 81679 Munich, Germany, office@cesifo.de)

2457 Andreas Knabe and Steffen Rätzel, Scarring or Scaring? The Psychological Impact of Past Unemployment and Future Unemployment Risk, November 2008

2458 John Whalley and Sean Walsh, Bringing the Copenhagen Global Climate Change Negotiations to Conclusion, November 2008

2459 Daniel Mejía, The War on Illegal Drugs in Producer and Consumer Countries: A Simple Analytical Framework, November 2008

2460 Carola Frydman, Learning from the Past: Trends in Executive Compensation over the Twentieth Century, November 2008

2461 Wolfgang Ochel, The Political Economy of Two-tier Reforms of Employment Protection in Europe, November 2008

2462 Peter Egger and Doina Maria Radulescu, The Influence of Labor Taxes on the Migration of Skilled Workers, November 2008

2463 Oliver Falck, Stephan Heblich and Stefan Kipar, The Extension of Clusters: Differencein-Differences Evidence from the Bavarian State-Wide Cluster Policy, November 2008

2464 Lei Yang and Keith E. Maskus, Intellectual Property Rights, Technology Transfer and Exports in Developing Countries, November 2008

2465 Claudia M. Buch, The Great Risk Shift? Income Volatility in an International Perspective, November 2008

2466 Walter H. Fisher and Ben J. Heijdra, Growth and the Ageing Joneses, November 2008

2467 Louis Eeckhoudt, Harris Schlesinger and Ilia Tsetlin, Apportioning of Risks via Stochastic Dominance, November 2008

2468 Elin Halvorsen and Thor O. Thoresen, Parents' Desire to Make Equal Inter Vivos Transfers, November 2008

2469 Anna Montén and Marcel Thum, Ageing Municipalities, Gerontocracy and Fiscal Competition, November 2008

2470 Volker Meier and Matthias Wrede, Reducing the Excess Burden of Subsidizing the Stork: Joint Taxation, Individual Taxation, and Family Splitting, November 2008

2471 Gunther Schnabl and Christina Ziegler, Exchange Rate Regime and Wage Determination in Central and Eastern Europe, November 2008 
2472 Kjell Erik Lommerud and Odd Rune Straume, Employment Protection versus Flexicurity: On Technology Adoption in Unionised Firms, November 2008

2473 Lukas Menkhoff, High-Frequency Analysis of Foreign Exchange Interventions: What do we learn?, November 2008

2474 Steven Poelhekke and Frederick van der Ploeg, Growth, Foreign Direct Investment and Urban Concentrations: Unbundling Spatial Lags, November 2008

2475 Helge Berger and Volker Nitsch, Gotcha! A Profile of Smuggling in International Trade, November 2008

2476 Robert Dur and Joeri Sol, Social Interaction, Co-Worker Altruism, and Incentives, November 2008

2477 Gaëtan Nicodème, Corporate Income Tax and Economic Distortions, November 2008

2478 Martin Jacob, Rainer Niemann and Martin Weiss, The Rich Demystified - A Reply to Bach, Corneo, and Steiner (2008), November 2008

2479 Scott Alan Carson, Demographic, Residential, and Socioeconomic Effects on the Distribution of $19^{\text {th }}$ Century African-American Stature, November 2008

2480 Burkhard Heer and Andreas Irmen, Population, Pensions, and Endogenous Economic Growth, November 2008

2481 Thomas Aronsson and Erkki Koskela, Optimal Redistributive Taxation and Provision of Public Input Goods in an Economy with Outsourcing and Unemployment, December 2008

2482 Stanley L. Winer, George Tridimas and Walter Hettich, Social Welfare and Coercion in Public Finance, December 2008

2483 Bruno S. Frey and Benno Torgler, Politicians: Be Killed or Survive, December 2008

2484 Thiess Buettner, Nadine Riedel and Marco Runkel, Strategic Consolidation under Formula Apportionment, December 2008

2485 Irani Arraiz, David M. Drukker, Harry H. Kelejian and Ingmar R. Prucha, A Spatial Cliff-Ord-type Model with Heteroskedastic Innovations: Small and Large Sample Results, December 2008

2486 Oliver Falck, Michael Fritsch and Stephan Heblich, The Apple doesn't Fall far from the Tree: Location of Start-Ups Relative to Incumbents, December 2008

2487 Cary Deck and Harris Schlesinger, Exploring Higher-Order Risk Effects, December 2008

2488 Michael Kaganovich and Volker Meier, Social Security Systems, Human Capital, and Growth in a Small Open Economy, December 2008 
2489 Mikael Elinder, Henrik Jordahl and Panu Poutvaara, Selfish and Prospective: Theory and Evidence of Pocketbook Voting, December 2008

2490 Maarten Bosker and Harry Garretsen, Economic Geography and Economic Development in Sub-Saharan Africa, December 2008

2491 Urs Fischbacher and Simon Gächter, Social Preferences, Beliefs, and the Dynamics of Free Riding in Public Good Experiments, December 2008

2492 Michael Hoel, Bush Meets Hotelling: Effects of Improved Renewable Energy Technology on Greenhouse Gas Emissions, December 2008

2493 Christian Bruns and Oliver Himmler, It's the Media, Stupid - How Media Activity Shapes Public Spending, December 2008

2494 Andreas Knabe and Ronnie Schöb, Minimum Wages and their Alternatives: A Critical Assessment, December 2008

2495 Sascha O. Becker, Peter H. Egger, Maximilian von Ehrlich and Robert Fenge, Going NUTS: The Effect of EU Structural Funds on Regional Performance, December 2008

2496 Robert Dur, Gift Exchange in the Workplace: Money or Attention?, December 2008

2497 Scott Alan Carson, Nineteenth Century Black and White US Statures: The Primary Sources of Vitamin D and their Relationship with Height, December 2008

2498 Thomas Crossley and Mario Jametti, Pension Benefit Insurance and Pension Plan Portfolio Choice, December 2008

2499 Sebastian Hauptmeier, Ferdinand Mittermaier and Johannes Rincke Fiscal Competition over Taxes and Public Inputs: Theory and Evidence, December 2008

2500 Dirk Niepelt, Debt Maturity without Commitment, December 2008

2501 Andrew Clark, Andreas Knabe and Steffen Rätzel, Boon or Bane? Others' Unemployment, Well-being and Job Insecurity, December 2008

2502 Lukas Menkhoff, Rafael R. Rebitzky and Michael Schröder, Heterogeneity in Exchange Rate Expectations: Evidence on the Chartist-Fundamentalist Approach, December 2008

2503 Salvador Barrios, Harry Huizinga, Luc Laeven and Gaëtan Nicodème, International Taxation and Multinational Firm Location Decisions, December 2008

2504 Andreas Irmen, Cross-Country Income Differences and Technology Diffusion in a Competitive World, December 2008

2505 Wenan Fei, Claude Fluet and Harris Schlesinger, Uncertain Bequest Needs and LongTerm Insurance Contracts, December 2008 
2506 Wido Geis, Silke Uebelmesser and Martin Werding, How do Migrants Choose their Destination Country? An Analysis of Institutional Determinants, December 2008

2507 Hiroyuki Kasahara and Katsumi Shimotsu, Sequential Estimation of Structural Models with a Fixed Point Constraint, December 2008

2508 Barbara Hofmann, Work Incentives? Ex Post Effects of Unemployment Insurance Sanctions - Evidence from West Germany, December 2008

2509 Louis Hotte and Stanley L. Winer, The Demands for Environmental Regulation and for Trade in the Presence of Private Mitigation, December 2008

2510 Konstantinos Angelopoulos, Jim Malley and Apostolis Philippopoulos, Welfare Implications of Public Education Spending Rules, December 2008

2511 Robert Orlowski and Regina T. Riphahn, The East German Wage Structure after Transition, December 2008

2512 Michel Beine, Frédéric Docquier and Maurice Schiff, International Migration, Transfers of Norms and Home Country Fertility, December 2008

2513 Dirk Schindler and Benjamin Weigert, Educational and Wage Risk: Social Insurance vs. Quality of Education, December 2008

2514 Bernd Hayo and Stefan Voigt, The Relevance of Judicial Procedure for Economic Growth, December 2008

2515 Bruno S. Frey and Susanne Neckermann, Awards in Economics - Towards a New Field of Inquiry, January 2009

2516 Gregory Gilpin and Michael Kaganovich, The Quantity and Quality of Teachers: A Dynamic Trade-off, January 2009

2517 Sascha O. Becker, Peter H. Egger and Valeria Merlo, How Low Business Tax Rates Attract Multinational Headquarters: Municipality-Level Evidence from Germany, January 2009

2518 Geir H. Bjønnes, Steinar Holden, Dagfinn Rime and Haakon O.Aa. Solheim, ,Large’ vs. ,Small' Players: A Closer Look at the Dynamics of Speculative Attacks, January 2009

2519 Jesus Crespo Cuaresma, Gernot Doppelhofer and Martin Feldkircher, The Determinants of Economic Growth in European Regions, January 2009

2520 Salvador Valdés-Prieto, The 2008 Chilean Reform to First-Pillar Pensions, January 2009

2521 Geir B. Asheim and Tapan Mitra, Sustainability and Discounted Utilitarianism in Models of Economic Growth, January 2009 